\title{
An Optimization Strategy for the Control of Small Capacity Heat
}

\section{Pump Integrated Air-conditioning System}

\author{
Jiajia Gao ${ }^{\mathrm{a}}$, Gongsheng Huang ${ }^{\mathrm{b}}$, Xinhua $\mathrm{Xu}^{\mathrm{a}}{ }^{\text {** }}$ \\ ${ }^{\text {a }}$ Department of Building Environment \& Energy Engineering, Huazhong University of \\ Science \& Technology, Wuhan, China \\ ${ }^{b}$ Department of Architecture and Civil Engineering, City University of Hong Kong, Kowloon, \\ Hong Kong, China \\ *Corresponding author, bexhxu@ hust.edu.cn
}

\begin{abstract}
This paper studies the optimization of a small-scale central air-conditioning system, in which the cooling is provided by a ground source heat pump (GSHP) equipped with an on/off capacity control. The optimization strategy aims to optimize the overall system energy consumption and simultaneously guarantee the robustness of the space air temperature control without violating the allowed GSHP maximum start-ups number per hour specified by customers. The set-point of the chilled water return temperature and the width of the water temperature control band are used as the decision variables for the optimization. The performance of the proposed strategy was tested on a simulation platform. Results show that the optimization strategy can save the energy consumption by $9.59 \%$ in a typical spring day and $2.97 \%$ in a typical summer day. Meanwhile it is able to enhance the space air temperature control robustness when compared with a basic control strategy without optimization.
\end{abstract}

Keyword: Ground source heat pump; Air-conditioning system; Optimization; Robustness; Maximum start-ups number; On/off control 


\section{Nomenclature}

$a_{0}-a_{3}, b_{0}-b_{1}, c_{0}-c_{3}$ Coefficients $\quad C \quad$ Thermal capacitance $(\mathrm{kJ} / \mathrm{K})$

c Specific heat $\{\mathrm{kJ} /(\mathrm{kg} \cdot \mathrm{K})$

$c_{p w} \quad$ Specific heat of water at constant pressure $\{\mathrm{kJ} /(\mathrm{kg} \cdot \mathrm{K})\}$

$h \quad$ Sampling interval (s) $\quad \mathrm{J} \quad$ Objective function

$M \quad$ Mass flow rate $(\mathrm{kg} / \mathrm{s})$

$\bar{M} \quad$ Maximum allowable bound of the mass flow rate $(\mathrm{kg} / \mathrm{s})$

$\underline{M}$ Minimum allowable bound of the mass flow rate $(\mathrm{kg} / \mathrm{s})$

$N_{\mathrm{c}} \quad$ Samplings in one cycle time $\quad N T U$ Number of transfer units

$N_{\text {start }}$ Allowed maximum start-ups number of the GSHP per hour

PLR Partial load ratio $\quad Q_{\mathrm{HP}} \quad$ Cooling capacity of heat pump (kW)

$\widehat{Q}_{\mathrm{HP}}$ Mean cooling capacity over the on time during on/off cycling period $(\mathrm{kW})$

$q \quad$ Cooling load $(\mathrm{kW})$

$\hat{q} \quad$ Mean value of the cooling load in one GSHP on/off cycling period $(\mathrm{kW})$

$T$ Temperature $\left({ }^{\circ} \mathrm{C}\right) \quad \bar{T} \quad$ Upper bound of the temperature $\left({ }^{\circ} \mathrm{C}\right)$

$\underline{T} \quad$ Lower bound of the temperature $\left({ }^{\circ} \mathrm{C}\right)$

$T^{\prime} \quad$ Temperature after introducing dynamic effects $\left({ }^{\circ} \mathrm{C}\right)$

$\Delta T_{\mathrm{w}}$ Width of the CHWR temperature control band $\left({ }^{\circ} \mathrm{C}\right)$

$t \quad$ Time (s)

$U A \quad$ Overall heat transfer coefficient $(\mathrm{kW} / \mathrm{K})$

$V \quad$ Volume $\left(\mathrm{m}^{3}\right)$

$\widehat{W} \quad$ Mean power consumption in one GSHP on/off cycling period $(\mathrm{kW})$

\section{Greek letters}

$\rho_{\mathrm{w}} \quad$ Water density $\left(\mathrm{kg} / \mathrm{m}^{3}\right)$ 


\section{Subscripts}

\begin{tabular}{|c|c|c|c|}
\hline $\mathrm{a}$ & Air & $\mathrm{cd}$ & Condenser \\
\hline $\mathrm{cl}$ & Cooling water & cyc & One cycle time \\
\hline down & Lower threshold & ev & Evaporator \\
\hline fan & Fan & GS & Ground source heat exchanger \\
\hline HP & Heat pump & in & Inside or inlet \\
\hline$k$ & Current time instant & $l$ & Total cooling load \\
\hline $\min$ & Minimum & off & Off \\
\hline on & On & out & Outlet \\
\hline pump & Pump & rated & Rated \\
\hline re & Return & sen & Sensible heat load \\
\hline set & Set value & soil & Soil \\
\hline sup & Supply & sys & System \\
\hline up & Upper threshold & w & Chilled water \\
\hline
\end{tabular}




\section{Introduction}

Air-conditioning (A/C) systems are widely used in buildings to provide safe and comfortable environment for building occupants. It has been shown that more than $40 \%$ of the building energy consumptions are mainly used for the heating, ventilation, and air-conditioning (HVAC) systems (ASHRAE 2009; Shen and Lukes 2015). In order to reduce the energy use of A/C systems, a number of optimization controls have been developed since 1980s, reviewed by ASHRAE handbook (2011). New developments since 2000 were surveyed by Afram and Janabi-Sharifi (2014). Generally, the basic components of optimizing A/C system framework are cost function, decision variables, and constraints (Huang and Wang et al. 2009; Sun et al. 2013).

Many optimization methods, including evolutionary algorithms (Sayyaadi et al. 2009, Kusiak et al. 2011), branch and bound (Chang et al. 2005, Ferreira et al. 2012) and simulated annealing (Chang et al. 2006, Spindler and Norford 2009), have been shown to be successful in minimizing energy consumption and reducing operation cost for $\mathrm{A} / \mathrm{C}$ systems. However, those optimization methods focus on multi-chiller plants with large capacity (Sun et al. 2013, Ling et al. 2012) or on commercial refrigeration plants (Sarabia et al 2007). Such systems are typically characterized by continuous capacity control, for example using optimal chiller sequencing control.

This paper studies the optimization of a small-scale A/C system integrated with a ground source heat pump (GSHP). Usually, a GSHP refers to a heat pump that uses the ground as a heat source and provides heat in cold winter, but it also refers to a heat pump that uses the ground as a heat sink and provides cooling in hot summer (Corberan et al. 2011). In this study, the cooling condition of the GSHP is concerned. Such a system is one common and fast 
growing system for heating/cooling small-scale buildings (Arteconi et al. 2013; Schibuola et al. 2013). Different from chiller plants with large capacity, the most common control method of small-scale GSHPs is an on/off control (Montagud et al. 2014). Many studies show that the annual efficiency of the intermittently operated heat pump may be higher than the variable-speed controlled heat pump (Karlsson and Fahlen 2007; Madani et al. 2011; Zhao et al. 2003). The on/off controlled GSHP is usually controlled according to the chilled water return (CHWR) temperature (i.e., the water temperature at the inlet of the GSHP evaporator) (Corberan et al. 2011). When the CHWR temperature is higher than a pre-defined upper threshold, the compressor will be switched on; while it will be switched off when the CHWR temperature is lower than a pre-defined lower threshold. Generally, the on/off threshold is set according to the set-point of the CHWR temperature $T_{\mathrm{w}, \mathrm{set}}$ and the allowed width of the differential between the on and off temperature $\Delta T_{\mathrm{w}}$ (see Eq. (1) for details) (Beghi and Cecchinato 2011).

There are two important issues in the on/off control of GSHP in practice. One is the GSHP start-ups number per hour, which should be concerned since frequent switch on/off will speed up the wear and aging of the device (Beghi and Cecchinato 2011). Another one is the significant disturbances introduced by the on/off control on the control loops of the $\mathrm{A} / \mathrm{C}$ system, which may deteriorate the stability of the control loops especially when the on/off switch is frequent (Corberan et al. 2011).Therefore, both issues should be taken into account when studying the energy efficiency of a GSHP integrated A/C system.

However, current relative studies did not consider both issues. For example, Corberan et al. (2011) studied the on/off control of a GSHP integrated A/C system and showed that the energy consumption of the GSHP reduces when the set-point of the CHWR temperature 
increases. Madani et al. (2013) compared three common methods to control an on/off controlled GSHP system and showed that the degree-minute method achieves the lowest energy use. Cervera-Vázquez et al. (2015) proposed an energy optimization strategy for a GSHP system and showed that a higher chilled water temperature set-point leads to more frequent on/off of the heat pump (Beghi and Cecchinato 2011). As the compressor on/off cycling frequency depends on the on/off threshold, Beghi and Cecchinato (2011) proposed an adaptive control to deal with the similar problem. In their study, $\Delta T_{w}$ and $T_{w, s e t}$ are regulated to improve the energy efficiency rating (EER) of the chiller based on the estimated cooling load subject to the allowed maximum number of compressor start-ups per hour. However, in their algorithm, the energy consumption of the air side system was not considered.

In this paper, a strategy is proposed for a GSHP-integrated $\mathrm{A} / \mathrm{C}$ system to minimize the overall system energy consumption subject to the allowed GSHP maximum start-ups number per hour specified by customers. Two steps are necessitated. Firstly, the water volume inside the chilled water loop is checked whether it is enough to satisfy the allowed GSHP maximum start-ups numbers per hour at the designed condition (i.e. $\Delta T_{\mathrm{w}}$ and $T_{\mathrm{w}, \text { set }}$ are the rated values). If not, a water tank is added to increase the water volume to the required minimum volume. Secondly, $\Delta T_{\mathrm{w}}$ and $T_{\mathrm{w}, \mathrm{set}}$ are optimized to minimize the overall system energy consumption according to the system operating load condition without violating the allowed GSHP maximum start-ups number and degrading the indoor temperature control performance.

\section{System Description and Control Issues}

\subsection{System description}

The GSHP-integrated central A/C system is illustrated in Fig. 1, where the GSHP is controlled by an on/off capacity controller $\mathrm{C} 1$. The cooling water is provided by a ground 
source heat exchanger (GSHE). The water flow rate in both the chilled water side and the cooling water side is constant. The supply air is conditioned by an air handle unit (AHU), which consists of the fresh air from outdoor and the returned air from the conditioned space. When the GSHP is on, the water is chilled down and delivered to the AHU to cool down the supply air. The supply air temperature is not under control and will vary with the variation of the chilled water supply temperature, which oscillates following the on/off operation of the GSHP. The supply air flow rate is controlled by a variable frequency drive (VFD) fan according to the room temperature measurement and its set point. The room is a common $\mathrm{A} / \mathrm{C}$ zone, and its temperature is controlled by a bilinear feedback controller C2 (Huang 2011), which tracks the set-point by regulating the supply air flow rate. Details are referred to the reference (Gao et al. 2015).

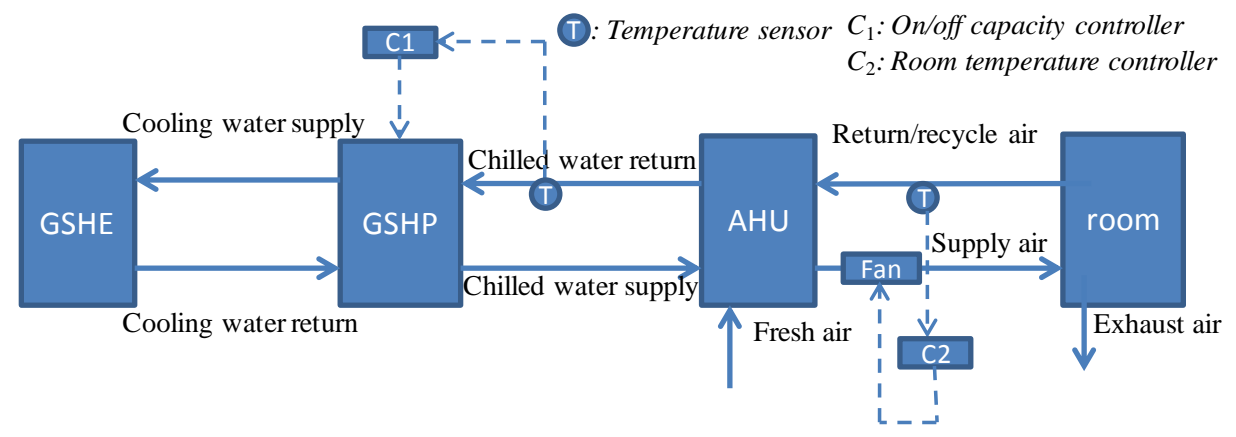

Fig. 1 Schematic diagram of the GSHP integrated central air-conditioning system

\subsection{Water volume and its influence on system performance}

It is known that the water volume inside the chilled water loop affects the on/off frequency of the compressor when the system operates at partial load. Generally at the same load condition, the on/off frequency will be higher when the water volume is less. Normally, the water volume is designed according to the cooling capacity of the system. Its design range is from about 3.9 to 7.8 litres per kilowatt in a typical HVAC system or up to 7.8 to 12.9 litres per kilowatt where temperature control accuracy is critical (Dawson 2007). This design does not 
consider the allowed maximum start-ups number of compressor per hour that may be specified by customers to protect their device (e.g. three or two times per hour). The specification of the allowed maximum start-ups number poses a constraint (a minimum value) on the water volume inside the chilled water loop. If the water volume is smaller than the required minimum water volume, a water tank is needed for increasing the water volume inside the chilled water loop to guarantee the allowed maximum start-ups number of compressor per hour specified by customers. It should be noted that when a water tank is added, it is fully integrated into the existing system without additional water volume control.

\subsection{Importance of the setting for the on-off capacity control of the GSHP}

When the water volume inside the chilled water loop is fixed, the performance of the system is mainly affected by the system control settings. In the on/off capacity control of a GSHP, the set-point of the CHWR temperature $T_{\mathrm{w}, \text { set }}$ and the width of the CHWR temperature control band $\Delta T_{\mathrm{w}}$ are normally used to determine the upper threshold (i.e. when the CHWR is higher than $T_{\text {w,up }}$, the GSHP is switched on) and the lower threshold (i.e. when the CHWR is lower than $T_{\mathrm{w}, \text { down }}$, the GSHP is switched off) as described in Eq. (1) (Beghi and Cecchinato 2011).

$$
T_{\text {w,up }}=T_{\text {w,set }}+\frac{\Delta T_{\mathrm{w}}}{2}, T_{\mathrm{w}, \text { down }}=T_{\mathrm{w}, \text { set }}-\frac{\Delta T_{\mathrm{w}}}{2}
$$

The set of $T_{\mathrm{w}, \text { set }}$ will affect the whole system energy and the number of the GSHP start-ups per hour. When $\Delta T_{\mathrm{w}}$ is a constant, a higher $T_{\mathrm{w}, \mathrm{set}}$ increases the cooling capacity and reduces the on time operation of the heat pump (Corberan et al. 2011), which can be exploited to reduce the heat pump energy use (Beghi and Cecchinato 2011). However, the mean supply air temperature increases following the increment of $T_{\mathrm{w}, \mathrm{set}}$. In order to maintain the space air temperature close to its set-point, the average operation frequency of the fan has to be enlarged to increase the supply air flow rate. Thus, the energy consumption of the fan 
increases. Therefore $T_{\mathrm{w}, \mathrm{set}}$ should be set by considering the overall system energy consumption. Besides, given a load the value of $T_{\mathrm{w}, \text { set }}$ will also affect the frequency of the GSHP switched on/off. A larger $T_{\mathrm{w}, \text { set }}$ will result in a larger start-ups number of the GSHP per hour. This is because for a given load the on time duration of the heat pump reduces with the increase of $T_{\mathrm{w}, \text { set }}$ while the off-time is relatively constant, and the period for one on/off cycle is reduced.

The set of $\Delta T_{\mathrm{w}}$ will also affect the number of the GSHP start-ups per hour. Given a $T_{\mathrm{w}, \mathrm{set}}$ and the load, $\Delta T_{\mathrm{w}}$ will affect the oscillating period of the CHWR temperature and hence the start-ups number of the GSHP (Beghi and Cecchinato 2011). A larger $\Delta T_{\mathrm{w}}$ value leads to a smaller number of the GSHP start-ups.

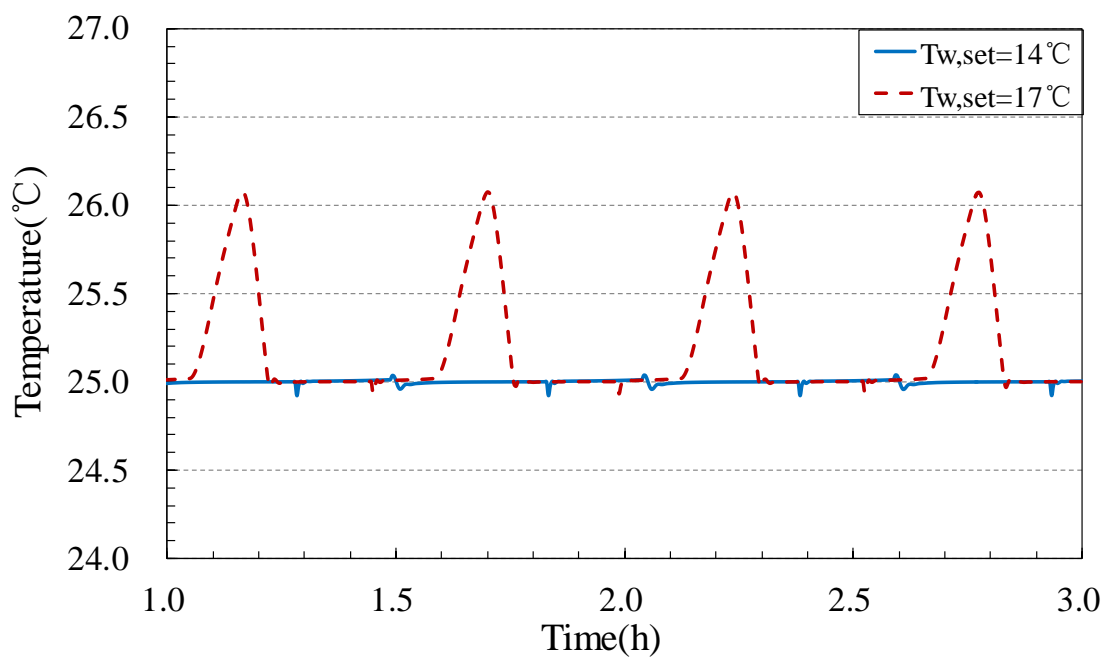

Fig. 2 Space temperature control performance with different settings of $T_{\mathrm{w}, \mathrm{set}}$ It is worth noticing that $T_{\mathrm{w}, \mathrm{set}}$ and $\Delta T_{\mathrm{w}}$ will also affect the terminal room temperature control. An example from a test on the test facility shown in Section 4.1 is given in Fig. 2, where the load was fixed and $\Delta T_{\mathrm{w}}$ was set to $6{ }^{\circ} \mathrm{C}$ and maintained a constant. When $T_{\mathrm{w}, \text { set }}$ was $14{ }^{\circ} \mathrm{C}$, the space air temperature can be maintained at the set-point very well; while it fluctuated significantly when $T_{\mathrm{w}, \text { set }}$ was changed to $17{ }^{\circ} \mathrm{C}$. Therefore, in order to improve the whole system energy performance, reduce the on/off cycling and enhance the room temperature 
control performance, $T_{\mathrm{w}, \text { set }}$ and $\Delta T_{\mathrm{w}}$ should be optimized, and an optimization scheme will be discussed in the next section.

\section{The Proposed Optimization Strategy}

Given a GSHP integrated A/C system and the specified allowed maximum start-ups number of the GSHP per hour by customers, the proposed optimization scheme is briefly illustrated below:

- Firstly, the water volume inside the chilled water loop will be checked whether it is enough to satisfy the allowed GSHP maximum start-ups number per hour specified by customers when the rated $T_{\mathrm{w}, \mathrm{set}}$ and $\Delta T_{\mathrm{w}}$ are used. To this end, the required minimum water volume $V_{\mathrm{w}, \mathrm{sys} \text {,min }}$ will be calculated according to the allowed GSHP maximum start-ups number and compared with the actual water volume $V_{\text {pip. }}$ If the actual value $V_{\text {pip }}$,

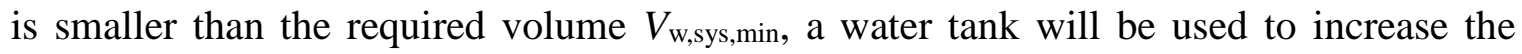
water volume to the required minimum water volume.

- Secondly, $T_{\mathrm{w}, \mathrm{set}}$ and $\Delta T_{\mathrm{w}}$ will be optimized online to minimize the overall system energy use according to the system operating load condition. To this end, the system energy model will be established, and an efficient way to solve the optimization will be identified. The GSHP maximum start-ups per hour specified by customers and the room temperature control performance will be taken as constraints in the optimization.

\subsection{Minimum chilled water volume of the system}

For a single GSHP with the on/off capacity control, the maximum number of the GSHP start-ups occurs when the cooling load is $50 \%$ of the GSHP rated cooling capacity (Beghi and Cecchinato 2011) (which can be derived from Eq.(8) as well), based on which the minimum chilled water volume is given by Eq. (2), where $t_{c y c, m i n}$ (in second) is the 
minimal on/off cycle time corresponding to the allowed GSHP maximum start-ups $N_{\text {start }}$ per hour, defined by Eq. (3).

$$
\begin{gathered}
V_{\mathrm{w}, \mathrm{sys}, \min }=\frac{t_{\mathrm{cyc}, \min } Q_{\mathrm{HP}, \text { rated }}}{4 \Delta T_{\mathrm{w}, \text { rated }} c_{p w} \rho_{\mathrm{w}}} \\
t_{\mathrm{cyc}, \min }=\frac{3600}{N_{\mathrm{start}}}
\end{gathered}
$$

Equation (2) is developed as follows. Firstly, according the energy balance of the chilled water, the CHWR temperature satisfies (Beghi and Cecchinato 2011)

$$
C_{\mathrm{w}} \frac{d T_{\mathrm{w}, \mathrm{re}}}{d t}=q_{l}-Q_{\mathrm{HP}}, \quad C_{\mathrm{w}}=c_{p w} \rho_{\mathrm{w}} V_{\mathrm{w}, \mathrm{sys}}
$$

where $C_{\mathrm{w}}$ is the thermal capacitance of the water inside the chilled water system $(\mathrm{kJ} / \mathrm{K}), c_{p w}$ is the water specific heat $(\mathrm{kJ} /(\mathrm{kg} \cdot \mathrm{K})), \rho_{\mathrm{w}}$ is the water density $\left(\mathrm{kg} / \mathrm{m}^{3}\right), V_{\mathrm{w}, \mathrm{sys}}$ is the water volume of the chilled water system $\left(\mathrm{m}^{3}\right), q_{l}$ is the total cooling load of the zone $(\mathrm{kW})$, and $Q_{\mathrm{HP}}$ is the cooling amount of the heat pump $(\mathrm{kW})$.

Using a sampling interval $h$, Eq. (4) is discretized as Eq. (5), where $k$ indicates the time instant. For a given total cooling load $q_{l}$, the on half-cycle $t_{\mathrm{on}}$, i.e. the time used for the CHWR temperature dropping from its upper threshold to its lower threshold, is calculated by Eq. (6). When the GSHP is switched off, $Q_{\mathrm{HP}}=0$ and the off half-cycle $t_{\mathrm{off}}$ is calculated by Eq. (7), where $\hat{Q}_{\mathrm{HP}}$ is the mean cooling capacity over the on time during on/off cycling period, $Q_{\mathrm{HP}, \text { rated }}$ is the rated cooling capacity of the GSHP at the designed condition, and PLR is the partial load ratio.

$$
\begin{gathered}
\frac{T_{\mathrm{w}, \mathrm{re}}^{k+1}-T_{\mathrm{w}, \mathrm{re}}^{k}}{h}=\frac{q_{l}^{k}-Q_{\mathrm{HP}}^{k}}{C_{\mathrm{w}}} \\
t_{\mathrm{on}}=\frac{\Delta T_{\mathrm{w}} C_{\mathrm{w}}}{\widehat{Q}_{\mathrm{HP}}-Q_{\mathrm{HP}, \text { rated }} P L R}, P L R=\frac{q_{l}}{Q_{\mathrm{HP}, \text { rated }}}
\end{gathered}
$$




$$
t_{\text {off }}=\frac{\Delta T_{\mathrm{w}} C_{\mathrm{w}}}{Q_{\mathrm{HP}, \text { rated }} P L R}
$$

As $T_{\mathrm{w}, \text { set }}$ and $\Delta T_{\mathrm{w}}$ are at their rated values, the GSHP will output its rated cooling capacity when it is on (i.e. $\hat{Q}_{\mathrm{HP}}=Q_{\mathrm{HP} \text {,rated }}$ ), the full cycle is given by Eq. (8). When $P L R=0.5$, the shortest cycle is reached as shown by Eq. (9), based on which the minimum water volume inside chilled water loop can be calculated by Eq. (2).

$$
\begin{gathered}
t_{\mathrm{cyc}}=t_{\mathrm{on}}+t_{\mathrm{off}}=\frac{\Delta T_{\mathrm{w}, \text { rated }} C_{\mathrm{w}}}{Q_{\mathrm{HP}, \text { rated }}}\left(\frac{1}{1-P L R}+\frac{1}{P L R}\right) \geq \frac{2 \Delta T_{\mathrm{w}, \text { rated }} C_{\mathrm{w}}}{Q_{\mathrm{HP}, \text { rated }}} \sqrt{\frac{1}{(1-P L R) P L R}} \\
t_{\mathrm{cyc}}=t_{\mathrm{cy}, \text { min }}=\frac{4 \Delta T_{\mathrm{w}, \text { rated }} C_{\mathrm{w}}}{Q_{\mathrm{HP}, \text { rated }}}
\end{gathered}
$$

If $V_{\mathrm{w}, \mathrm{ys}, \min }>V_{\text {pip }}$, a water tank is needed and the system structure becomes Fig. 3. The minimum size of the water tank for the system can be computed by Eq. (10). When $T_{\mathrm{w}, \text { set }}$ and $\Delta T_{\mathrm{w}}$ are the rated values, this size of the water tank can satisfy the allowed maximum start-ups number of the compressor at any cooling load condition.

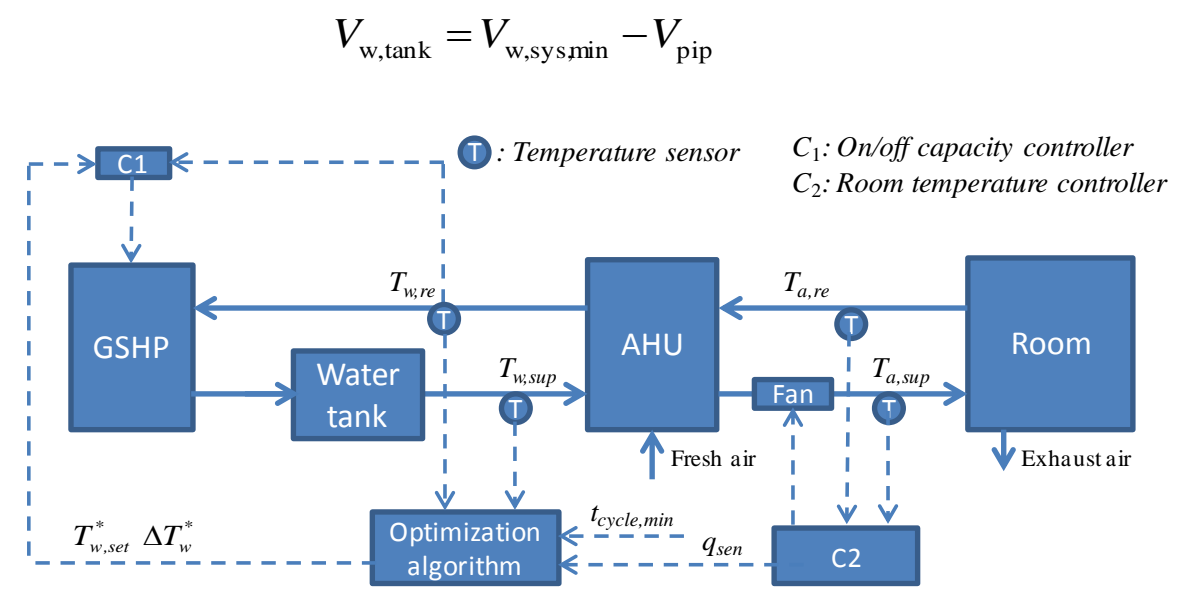

Fig. 3 Schematic diagram of optimization

\subsection{Optimization of $T_{w, s e t}$ and $\Delta T_{w}$}

After the water volume in the chilled water loop is checked and retrofitted (if necessary), the 
next step is to optimize $T_{\mathrm{w}, \mathrm{set}}$ and $\Delta T_{\mathrm{w}}$. The objective of this optimization is to minimize the overall energy consumption of the system subject to the constraints (1) the GSHP maximum start-ups per hour specified by customers and (2) the allowed variation of the chilled water return temperature. Thus, the optimization is formulated as

$$
\left(T_{\mathrm{w}, \mathrm{set}}^{*}, \Delta T_{\mathrm{w}}^{*}\right)=\arg \min J\left(T_{\mathrm{w}, \mathrm{set}}, \Delta T_{\mathrm{w}}\right)
$$

subject to the constraints (12) - (16):

$$
\begin{gathered}
T_{\mathrm{w}, \mathrm{set}}+\Delta T_{\mathrm{w}} / 2 \leqslant \bar{T}_{\mathrm{w}, \mathrm{re}} \\
T_{\mathrm{w}, \mathrm{set}}-\Delta T_{\mathrm{w}} / 2 \geqslant \underline{T}_{\mathrm{w}, \mathrm{re}} \\
t_{\mathrm{cyc}}=t_{\mathrm{on}}+t_{\mathrm{off}} \geqslant t_{\mathrm{cyc}, \min } \\
t_{\mathrm{on}} \geqslant t_{\mathrm{on}, \min } \\
t_{\mathrm{off}} \geqslant t_{\mathrm{off}, \min }
\end{gathered}
$$

where $J$ is the objective function; $t_{\mathrm{on}, \min }$ and $t_{\mathrm{off}, \min }$ are the allowed minimum on time and the allowed minimum off time which are given by the compressor manufacturer to safeguard the compressor; $\bar{T}_{\mathrm{w}, \mathrm{re}}$ and $\underline{T}_{\mathrm{w}, \mathrm{re}}$ will be specified according to the room temperature control, detailed in the subsection 'constraints of optimization'.

\section{Objective function}

The average power consumption of the overall system in one GSHP on/off cycle is used as the objective function, which is defined as

$$
J=\widehat{W}_{\text {sys }}=\widehat{W}_{\mathrm{HP}}+\widehat{W}_{\mathrm{pump}}+\widehat{W}_{\text {fan }}
$$

where $\widehat{W}_{\text {sys }}$ is the average power of the overall system in one cycle $(\mathrm{kW})$. Since the power is correlated to the CHWR temperature set-point, the space air temperature set-point and the $P L R, \widehat{W}_{\text {sys }}$ is calculated using the following empirical formula (titled as the GSHP mean 
power model in one on/off cycle).

$$
\widehat{W}_{\mathrm{sys}}=c_{0}\left(T_{\mathrm{a}, \mathrm{set}}-T_{\mathrm{w}, \mathrm{set}}\right)^{2}+c_{1}\left(T_{\mathrm{a}, \mathrm{set}}-T_{\mathrm{w}, \mathrm{set}}\right) P L R+c_{2}\left(\frac{P L R}{T_{\mathrm{a}, \mathrm{set}}-T_{\mathrm{w}, \mathrm{set}}}\right)^{2}+c_{3}
$$

where $T_{\mathrm{a} \text {,set }}$ is the space air temperature set-point, which is fixed in this study; $T_{\mathrm{w}, \text { set }}$ is the CHWR temperature set-point; and $c_{0}-c_{3}$ are coefficients that should be identified using the operation data.

\section{Constraints of optimization}

The constraints shown by Eqs. (12) and (13) are developed based on the assumption that when the GSHP is on, the cooling provided by the AHU can fulfil the required cooling demand (only sensible load is concerned) and local controller can well track the room temperature set-point. In this case, the supply air temperature satisfies

$$
M_{\mathrm{a}} c_{\mathrm{a}}\left(T_{\mathrm{a}, \mathrm{set}}-T_{\mathrm{a}, \text { sup }}\right)=q_{\text {sen }}
$$

The room temperature can be maintained at its set point by adjusting the supply air flow rate.

As the supply air flow rate is limited into the range $\left(\underline{M}_{\mathrm{a}}, \bar{M}_{\mathrm{a}}\right)$, the supply air temperature should also be limited into the range of

$$
\underline{T}_{\mathrm{a}, \text { sup }} \leq T_{\mathrm{a} \text {,sup }} \leq \bar{T}_{\mathrm{a}, \text { sup }}
$$

where the lower and upper bounds are given by

$$
\begin{gathered}
\underline{T}_{\mathrm{a} \text { sup }}=T_{\mathrm{a}, \text { set }}-q_{\text {sen }} /\left(\underline{M}_{\mathrm{a}} c_{\mathrm{a}}\right) \\
\bar{T}_{\mathrm{a} \text {,sup }}=T_{\mathrm{a}, \text { set }}-q_{\text {sen }} /\left(\bar{M}_{\mathrm{a}} c_{\mathrm{a}}\right)
\end{gathered}
$$

As the supply air temperature is affected by the CHWR temperature, an empirical formula (i.e., the simplified AHU model) is used to describe the relationship between the CHWR temperature and the AHU supply air temperature (Ma and Wang 2009), shown below

$$
T_{\mathrm{w}, \mathrm{re}}=a_{0} T_{\mathrm{a}, \mathrm{sup}}^{a_{1}} q_{l}^{a_{2}} M_{\mathrm{a}}^{a_{3}}
$$


where $a_{0}-a_{3}$ are the parameters that should be identified by the system operating data. Then, $\bar{T}_{\mathrm{w}, \mathrm{re}}$ and $\underline{T}_{\mathrm{w}, \mathrm{re}}$ are calculated by

$$
\begin{aligned}
& \bar{T}_{\mathrm{w}, \mathrm{re}}=a_{0} \bar{T}_{\mathrm{a}, \mathrm{sup}}^{a_{1}} q_{l}^{a_{2}} \bar{M}_{\mathrm{a}}^{a_{3}} \\
& \underline{T}_{\mathrm{w}, \mathrm{re}}=a_{0} \underline{T}_{\mathrm{a}, \mathrm{sup}}^{a_{1}} q_{l}^{a_{2}} \underline{M}_{\mathrm{a}}^{a_{3}}
\end{aligned}
$$

where $\bar{T}_{\mathrm{a} \text {,sup }}$ and $\underline{T}_{\mathrm{a} \text {,sup }}$ are the upper and lower bound of the supply air temperature catering to the sensible heat load.

The constraint specified by Eq. (14) is developed to limit the start-ups number of the GSHP. The constraints specified by Eqs. (15) and (16) are used to safeguard the compressor, which are given by the compressor manufacturer. When $T_{\mathrm{w}, \mathrm{set}}$ changes, the mean cooling capacity over the on time during on/off cycling period, $\widehat{Q}_{\mathrm{HP}}$, will change, which affects the length of the heat pump operating time as shown in Eq. (6). Therefore, the relationship between $\hat{Q}_{\mathrm{HP}}$ and $T_{\mathrm{w}, \text { set }}$ is important for the constraints of Eqs. (14)-(16).

In this study, the heat accumulation in the soil is ignored in a short time period, and the thermal process of the GSHE is assumed to be constant. Thus the cooling water temperature at the GSHE outlet in the GSHP on period is relatively steady, and the variation may be within $0.5{ }^{\circ} \mathrm{C}$. The effect of the cooling water temperature on $\hat{Q}_{\mathrm{HP}}$ is not obvious and may be neglected. $\hat{Q}_{\mathrm{HP}}$ is seriously affected by $T_{\mathrm{w}, \text { set, }}$, and can be predicted by using the model of Eq. (26) (called as the mean cooling capacity model over the on time during on/off cycling period).

$$
\widehat{Q}_{\mathrm{HP}}=b_{0} T_{\mathrm{w}, \mathrm{set}}^{b_{1}}
$$

\subsection{Load estimation}

As shown in Eqs. (4), (18), (19) and (23), $T_{\mathrm{w}, \text { set }}$ and $\Delta T_{\mathrm{w}}$ are optimized according to the load 
condition. Since the optimization works based on the GSHP on/off cycling period, the average cooling load in one cycle calculated by Eq. (27) is used to assess the load condition, where $\hat{q}_{l}$ indicates the mean value of the total cooling load in one cycle, $\hat{q}_{\text {sen }}$ indicates the mean value of the sensible heat load in one cycle, and $N_{\mathrm{c}}$ is the samplings in one cycle and its value is determined by the length of the cycle period.

$$
\hat{q}_{l}=\frac{1}{N_{c}}\left(\sum_{i=0}^{N_{c}-1} q_{l, k-i}\right), \hat{q}_{s e n}=\frac{1}{N_{c}}\left(\sum_{i=0}^{N_{c}-1} q_{s e n, k-i}\right)
$$

The real-time total cooling load $q_{l, k}$ is calculated by Eq. (28) based on the energy balance between the water side and the air side of the AHU. This simple way is used based on the assumption that the thermal loads affecting the GSHP system is only produced by AHU.

$$
q_{l, k}=M_{\mathrm{w}} c_{p w}\left(T_{\mathrm{w}, \mathrm{re}, k}-T_{\mathrm{w}, \mathrm{sup}, k}\right)
$$

where $M_{\mathrm{w}}$ is the chilled water flow rate which is constant, $T_{\mathrm{w}, \text { sup }}$ is the water temperature at the inlet of the AHU (i.e. the chilled water supply temperature). $T_{\mathrm{w}, \mathrm{re}}$ is the CHWR temperature assumed to be the water temperature measured at the outlet of the AHU. The subscript $k$ indicates the current time instant. Similarly, one simple way to calculate the real-time sensible heat load $q_{s e n, k}$ at steady state is used based on the circulating air energy balance as shown in Eq. (29), which will be used in Eq. (27) and then in Eqs. (21-22).

$$
q_{\text {sen, }, k}=c_{\mathrm{a}} M_{\mathrm{a}, k}\left(T_{\mathrm{a}, \mathrm{re}, k}-T_{\mathrm{a}, \mathrm{sup}, k}\right)
$$

\subsection{Optimization algorithm}

The optimization algorithm is summarized below:

\section{Offline}

Initialize the counter $N_{c}$ to zero, and set the initial values of $\hat{q}_{l}$ and $\hat{q}_{s e n}$.

Online operation (at each sampling time) 
Step 1: Measure $T_{\mathrm{a}, \mathrm{re}, k}, T_{\mathrm{a}, \mathrm{sup}, k}, m_{\mathrm{a}, k}, T_{\mathrm{w}, \mathrm{re}, k}, T_{\mathrm{w}, \mathrm{sup}, k}$ and calculate the real-time total cooling load $q_{l, k}$ by Eq. (28) and sensible heat load $q_{s e n, k}$ by Eq. (29), and increase $N_{c}$ by 1 ;

Step 2: Check the status of the GSHP:

If the status changes from 'off' to 'on', calculate the mean total cooling load $\hat{q}_{l}$ and the mean sensible heat load $\hat{q}_{s e n}$ by Eq. (27), and reset $N_{c}$ to zero. Calculate the optimal values of $T_{\mathrm{w}, \mathrm{set}}^{*}$ and $\Delta T_{\mathrm{w}}^{*}$ by Eq. (11);

If the status does not change or the status changes 'on' to 'off', maintain the values of $\hat{q}_{l}, \hat{q}_{s e n}, N_{\mathrm{c}}, T_{\mathrm{w}, \mathrm{set}}^{*}$ and $\Delta T_{\mathrm{w}}^{*}$

Step 3: Apply $T_{\mathrm{w}, \mathrm{set}}^{*}$ and $\Delta T_{\mathrm{w}}^{*}$ to the on/off controller and wait for the next sampling time.

For this optimization algorithm, the inputs include the cooling load calculated by Eq. (28) and the sensible heat load calculated by Eq. (29). The outputs are $T_{\mathrm{w}, \text { set }}$ and $\Delta T_{\mathrm{w}}$, which will be used to control the on/off of the GSHP by resetting the on/off threshold according to Eq. (1).

\section{Construction of the simulation platform}

\subsection{Test facility}

A simulated virtual system representing an actual GSHP-integrated central A/C system, as shown in Fig. 4, was used to test the performance of the optimization strategy. The air-conditioning room has the area of $50 \mathrm{~m}^{2}$, which may represent an ordinary A/C zone. The load conditions of the room are presented in Section 5.1. The technique data of the GSHP-integrated $\mathrm{A} / \mathrm{C}$ system are given in Table 1. According to the rated CHWR temperature set-point and the rated band width of the CHWR temperature control band, the GSHP will be switched on when the CHWR is larger than $15{ }^{\circ} \mathrm{C}$ while off when the CHWR is smaller than $9{ }^{\circ} \mathrm{C}$.The supply air fan is equipped with a variable frequency drive, and the operation frequency can be adjusted. This test rig is also installed with a set of monitoring 
and control system. The parameters of sensors and actuators are listed in Table 2. By this building automation system (BAS), chilled/cooling water supply/return temperature and air supply/return temperature can be measured and recorded automatically with specified time interval.

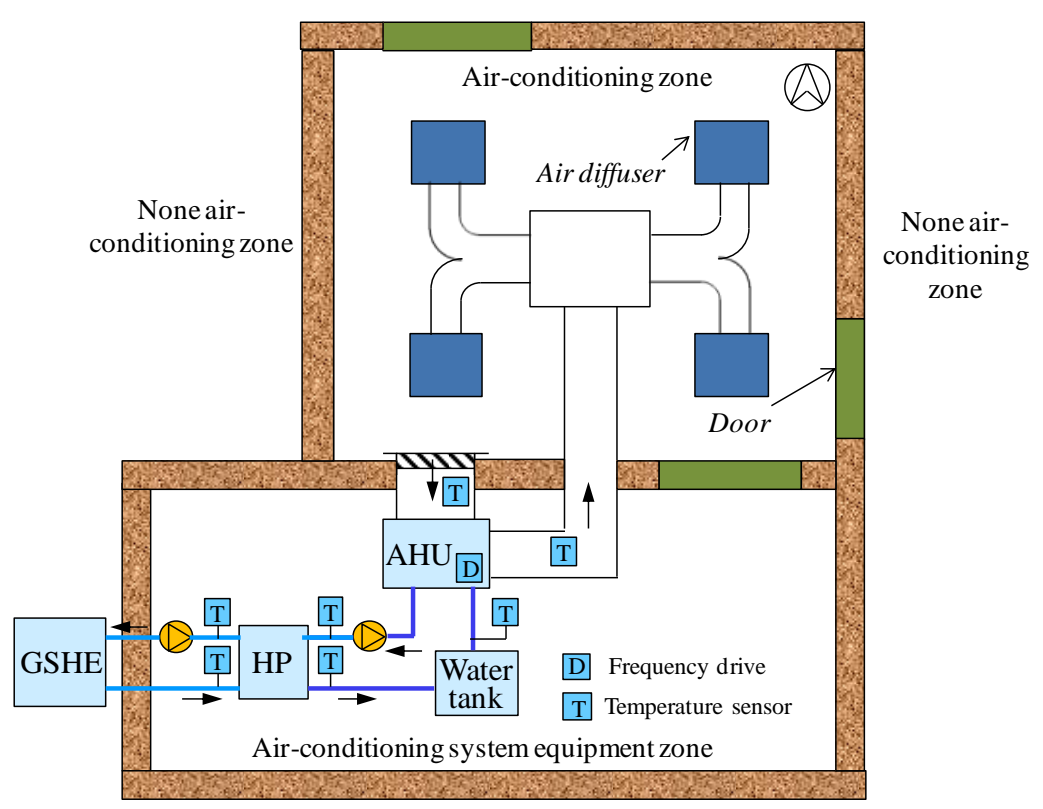

Fig. 4 Layout of the GSHP integrated A/C system

Table 1 Technique data of the GSHP-integrated A/C system

\section{GSHP}

Compressor type

Evaporator, condenser type

Expansion value

Refrigerant

Rated cooling capacity

Rated input power

Rated CHWR temperature set-point

Rated band width of the CHWR temperature

control band
Scroll compressor

Tube-in-tube heat exchangers

A common thermostatic expansion valve

R22

$17.2 \mathrm{~kW}$

$3.91 \mathrm{~kW}$

$12{ }^{\circ} \mathrm{C}$

$\pm 3{ }^{\circ} \mathrm{C}$ 
Rated chilled water flow

Rated cooling water flow

Chilled water pump rated power

Cooling water pump rated power
$0.822 \mathrm{~kg} / \mathrm{s}$

$1.006 \mathrm{~kg} / \mathrm{s}$

$0.292 \mathrm{~kW}$

$0.475 \mathrm{~kW}$

\section{Air-handling unit}

\begin{tabular}{ll}
\hline Rated air flow rate & $3000 \mathrm{~m}^{3} / \mathrm{h}$ \\
Supply air fan rated power & $1.1 \mathrm{~kW}$ \\
Supply air fan frequency & $15 \mathrm{~Hz}$ to $50 \mathrm{~Hz}$ \\
\hline
\end{tabular}

Table 2 Description of sensor and actuator

\begin{tabular}{cccc}
\hline Sensor/Actuator & Signal type & Range & Accuracy \\
\hline Air temperature sensor & $10 \mathrm{~K}$ ohm & $0-70{ }^{\circ} \mathrm{C}$ & $\pm 0.1^{\circ} \mathrm{C}$ \\
Water temperature sensor & $4-20 \mathrm{~mA}$ & $0-50{ }^{\circ} \mathrm{C}$ & $\pm 0.1^{\circ} \mathrm{C}$ \\
Fan frequency drive & $0-10 \mathrm{~V}$ & $0-50 \mathrm{~Hz}$ & - \\
\hline
\end{tabular}

\subsection{Simulation platform}

The software TRNSYS (TRNSYS 2004) was used to construct the simulation platform as shown in Fig. 5. The models used in this simulation platform include a building model, a GSHP model, an AHU model, water pump models, a water tank model, a ground source heat exchanger (GSHE) model, a cooling coil control valve model, temperature and humidity sensor models and an actuator model etc. The optimization algorithm was coded using MATLAB, which are embedded in TRNSYS by the component Type 155. Two local controllers, an on/off controller and a bilinear feedback controller, were used control the heat pump and the room temperature respectively. 


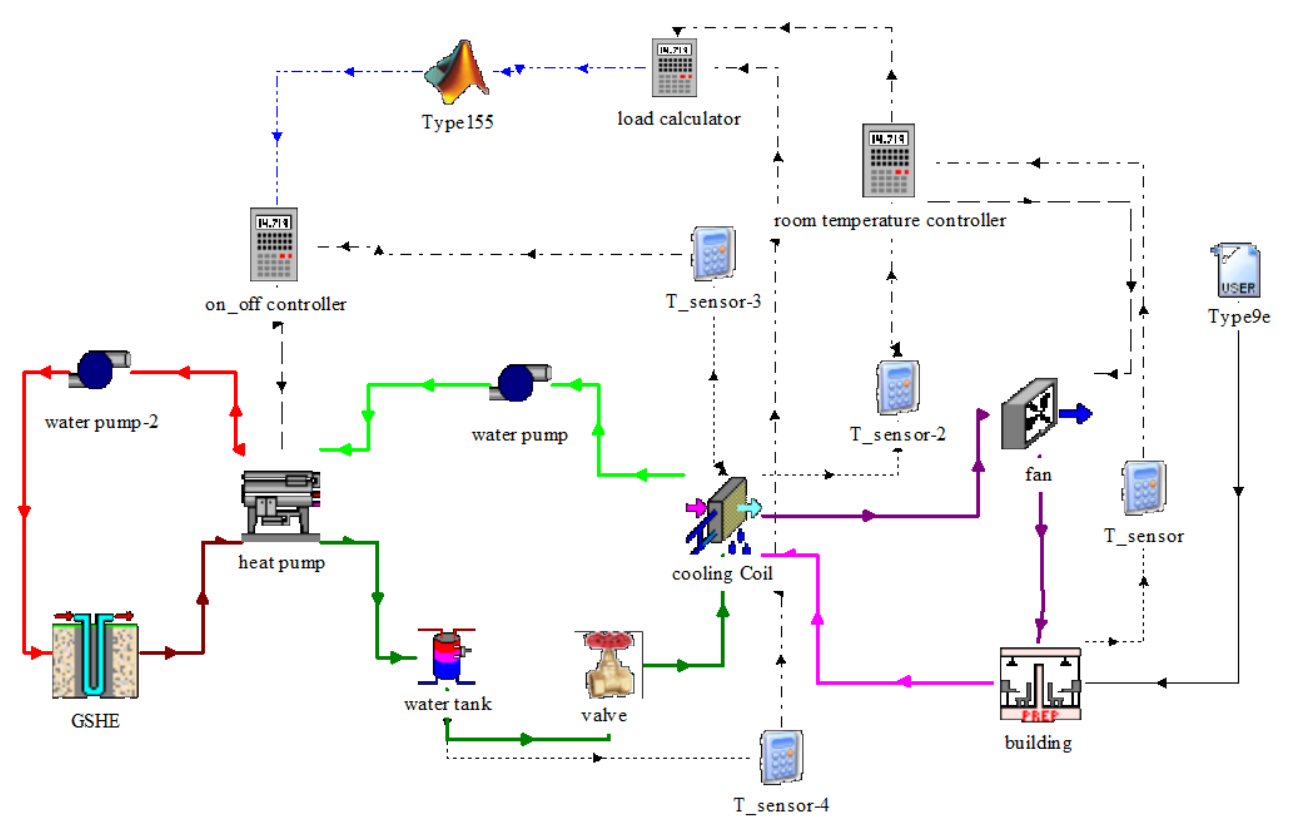

Fig. 5 Simulation platform of the GSHP integrated A/C system

\subsection{Main models used in the simulation platform}

\section{Building model}

The building model adopted in this study is a simplified model simulating the dynamic balance of energy and moisture of the building system. The model represents the A/C room using a thermal network with thermal resistance, thermal capacitance and air volume. The external and internal walls of the room are represented by a two-node model to link the space with outside or the neighbor rooms. The internal mass such as furniture in the room is represented by another two-node model. Detailed model description and the building configuration can be found in Ref (Gao et al. 2015).

\section{Heat pump dynamic model}

The GSHP dynamic model includes the steady-state model (includes the motor power consumption model and the evaporator and condenser heat exchanger model) and the first-order inertia process in the evaporator and condenser. The steady-state model is a 
quasi-physical model (Bourdhouxhe et al. 1999). The power of the compressor $W_{\text {com }}$ is calculated by Eqn. (30), where $W_{\text {in }}$ is the internal work of the compressor, $W_{\text {lo }}$ is a constant portion of the electromechanical losses, and $\alpha$ is a loss factor allowing for the definition another electromechanical loss which is assumed to be proportional to the internal power. Both the evaporator and the condenser were modeled using the $\varepsilon$-NTU method, described by Eqns. (31)-(34), where $Q$ is the heat exchange amount, and $U A$ is the overall heat transfer coefficient, which is considered to be constant.

$$
\begin{gathered}
W_{\mathrm{com}}=W_{\mathrm{in}}+\alpha W_{\mathrm{in}}+W_{\mathrm{lo}} \\
\varepsilon_{\mathrm{ev}}=1-\exp \left(-N T U_{\mathrm{ev}}\right), N T U_{\mathrm{ev}}=\frac{U A_{\mathrm{ev}}}{c_{\mathrm{pw}} M_{\mathrm{w}}} \\
Q_{\mathrm{ev}}=\varepsilon_{\mathrm{ev}} c_{\mathrm{pw}} M_{\mathrm{w}}\left(T_{\mathrm{w}, \mathrm{in}}-T_{\mathrm{ev}}\right) \\
\varepsilon_{\mathrm{cd}}=1-\exp \left(-N T U_{\mathrm{cd}}\right), N T U_{\mathrm{cd}}=\frac{U A_{\mathrm{cd}}}{c_{\mathrm{pw}} M_{\mathrm{cl}}} \\
Q_{\mathrm{cd}}=\varepsilon_{\mathrm{cd}} c_{\mathrm{pw}} M_{\mathrm{cl}}\left(T_{\mathrm{cd}}-T_{\mathrm{cl}, \mathrm{in}}\right)
\end{gathered}
$$

The first-order inertia model in the Ref. (Wang et al. 2000) is used to simply represent the dynamic response of the GSHP with lumped thermal mass, shown by Eqs. (35)-(38), where $T$ and $T^{\prime}$ are the water temperature at inlet and outlet of the thermal storage, respectively. $C$ is the thermal capacitance, and only the thermal capacitances of the water volume in the evaporator and condenser are concerned.

$$
\begin{gathered}
C_{\mathrm{ev}, \text { out }} \frac{d T_{\mathrm{w}, \text { out }}^{\prime}}{d t}=c_{p w} M_{\mathrm{w}}\left(T_{\mathrm{w}, \text { out }}-T_{\mathrm{w}, \text { out }}^{\prime}\right) \\
C_{\mathrm{cd}, \text { out }} \frac{d T_{\mathrm{cl}, \text { out }}^{\prime}}{d t}=c_{p w} M_{\mathrm{cl}}\left(T_{\mathrm{cl}, \text { out }}-T_{\mathrm{cl}, \text { out }}^{\prime}\right) \\
C_{\mathrm{ev}, \text { in }} \frac{d T_{\mathrm{w}, \text { in }}^{\prime}}{d t}=c_{p w} M_{\mathrm{w}}\left(T_{\mathrm{w}, \text { in }}^{\prime}-T_{\mathrm{w}, \text { in }}\right)
\end{gathered}
$$




$$
C_{\mathrm{cd}, \mathrm{in}} \frac{d T_{\mathrm{cl}, \mathrm{in}}^{\prime}}{d t}=c_{p w} M_{\mathrm{cl}}\left(T_{\mathrm{cl}, \mathrm{in}}^{\prime}-T_{\mathrm{cl}, \mathrm{in}}\right)
$$

\section{$\underline{\text { GSHE model }}$}

The GSHE associated with the GSHP system is modeled by using a NTU model as Eq. (39), where $T_{\text {soil }}$ is the soil temperature, and $U A_{\mathrm{GS}}$ is the overall heat transfer coefficient of the GSHE which is considered to be a constant. Since the operation of the air-conditioning system is not continuously, the hot stack is not considered in this GSHE model.

$$
T_{\mathrm{GS}, \text { out }}=T_{\text {soil }}+\frac{T_{\mathrm{GS}, \text { in }}-T_{\text {soil }}}{\exp ^{N T U_{\mathrm{GS}}}}, N T U_{\mathrm{GS}}=\frac{U A_{\mathrm{GS}}}{c_{p w} M_{\mathrm{cl}}}
$$

\section{$\underline{\text { AHU model }}$}

The adopted AHU model consists of a wet cooling coil model and a fan model (Wang 1999). The flow characteristic of the cooling coil valve is of equal percentage with dead bands (Xu et al. 2004). The basic law of fluid mechanics is used for the fan model (Gao et al. 2015). Dynamic sensor models are used to simulate the temperature, humidity sensors using time constant method. An actuator model is used to simulate the realistic characteristics of the actuators. The actuator is assumed to accelerate very quickly and then turn at constant speed (Haves and Dexter 1989). The water pump model is a constant speed pump model. A water tank provides thermal inertia within the system, and a simplified tank model from Ref. (Corberan et al. 2011) is used as shown by Eq. (40), where $\rho_{\mathrm{w}}$ is the water density. The temperature in the water tank $T_{\mathrm{w}, \mathrm{tank}}$ is considered to be uniform, and the heat loss from the tank is ignored.

$$
\frac{d T_{\mathrm{w}, \mathrm{tank}}}{d t}=\frac{M_{\mathrm{w}}\left(T_{\mathrm{w}, \text { out }}-T_{\mathrm{w}, \operatorname{tank}}\right)}{V_{\mathrm{w}, \operatorname{tank}} \rho_{\mathrm{w}}}
$$




\subsection{Validation of the heat pump model and the GSHE model}

Before testing the control algorithm, the heat pump model and the GSHE model were validated using the operation data collected from the test rig. To this end, the test rig was running in several summer days and the data collected in July 7 were used to identify the parameters of the heat pump model and the GSHE model. The outdoor temperature varied from $23^{\circ} \mathrm{C}$ to $32{ }^{\circ} \mathrm{C}$ and the relative humidity varied from $66 \%$ to $95 \%$ (a typical summer day in Wuhan). The indoor load varied from $5 \mathrm{~kW}$ (night) to $15 \mathrm{~kW}$.

In the heat pump model, the input variables are the inlet chilled/cooling water temperature as well as the chilled/cooling water flow rate. The output variables are the outlet chilled/cooling water temperature and the power consumption. In the steady-state model, the parameters need to be determined are $\alpha, W_{\mathrm{lo}}, U A_{\mathrm{ev}}$ and $U A_{\mathrm{cd}}$, and their identified values are listed in Table 3 . For the dynamic model (Eqs. (35)-(38)), as the water volume in the evaporator was about 15 $\mathrm{L}$ and that in the condenser was about $20 \mathrm{~L}$, the thermal capacitances (i.e., $C_{\mathrm{ev}, \text { in }}, C_{\mathrm{ev}, \text { out }}, C_{\mathrm{cd}, \text { in }}$ and $C_{\text {cd,out }}$ ) used in the heat pump dynamic model were calculated and listed in Table 4.

Table 3 Parameters of the heat pump

\begin{tabular}{ccccc}
\hline Parameters & $U A_{\mathrm{cd}}(\mathrm{kW} / \mathrm{K})$ & $U A_{\mathrm{ev}}(\mathrm{kW} / \mathrm{K})$ & $\alpha$ & $W_{\mathrm{lo}}(\mathrm{kW})$ \\
\hline Value & 3.0371 & 2.6786 & -0.3716 & 2.7762 \\
\hline
\end{tabular}

Table 4 Thermal capacitances used in the heat pump dynamic model

\begin{tabular}{ccc}
\hline Thermal capacitance & Inlet $(\mathrm{kJ} / \mathrm{K})$ & Outlet $(\mathrm{kJ} / \mathrm{K})$ \\
\hline Evaporator side & 31.5 & 31.5 \\
Condenser side & 42 & 42 \\
\hline
\end{tabular}

The model was validated using the data collected in another summer day (other than July 7). 
As an example, the measured CHWR temperature and cooling water return temperature, the input variables of the heat pump model in July 9, are plotted in Fig. 6(a). It can be seen that the cooling water temperature at the inlet of the condenser $T_{\mathrm{cl} \text {,in }}$ was stable (around $22{ }^{\circ} \mathrm{C}$ ). The CHWR temperature varied between $11{ }^{\circ} \mathrm{C}$ and $19{ }^{\circ} \mathrm{C}$ with the on/off of the GSHP, where the CHWR temperature set-point $T_{\mathrm{w}, \text { set }}$ was set as $15{ }^{\circ} \mathrm{C}$, and $\Delta T_{\mathrm{w}}$ as $6{ }^{\circ} \mathrm{C}$ (Ideally $T_{\text {w,in }}$ should vary between $12{ }^{\circ} \mathrm{C}$ and $18{ }^{\circ} \mathrm{C}$; and the slightly difference may due to inertia in the system dynamics). In Fig. 6(b), the predicted power consumption as well as the predicted chilled water supply temperature by using the GSHP model was compared with the measurements from the test rig. The maximum mean deviation of the compressor power consumption in one cycle is $2.46 \%$, and the maximum mean deviation of the chilled water temperature at the evaporator outlet is $4.45 \%$. The GSHP model may predict the outlet water temperature and power consumption accurately.

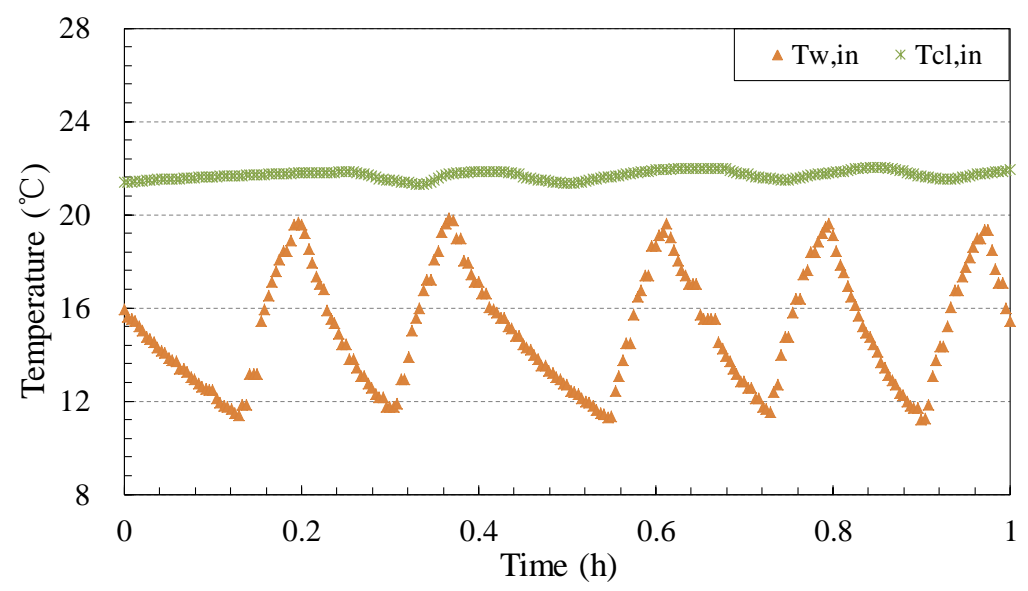

(a) Input variables of the GSHP model 


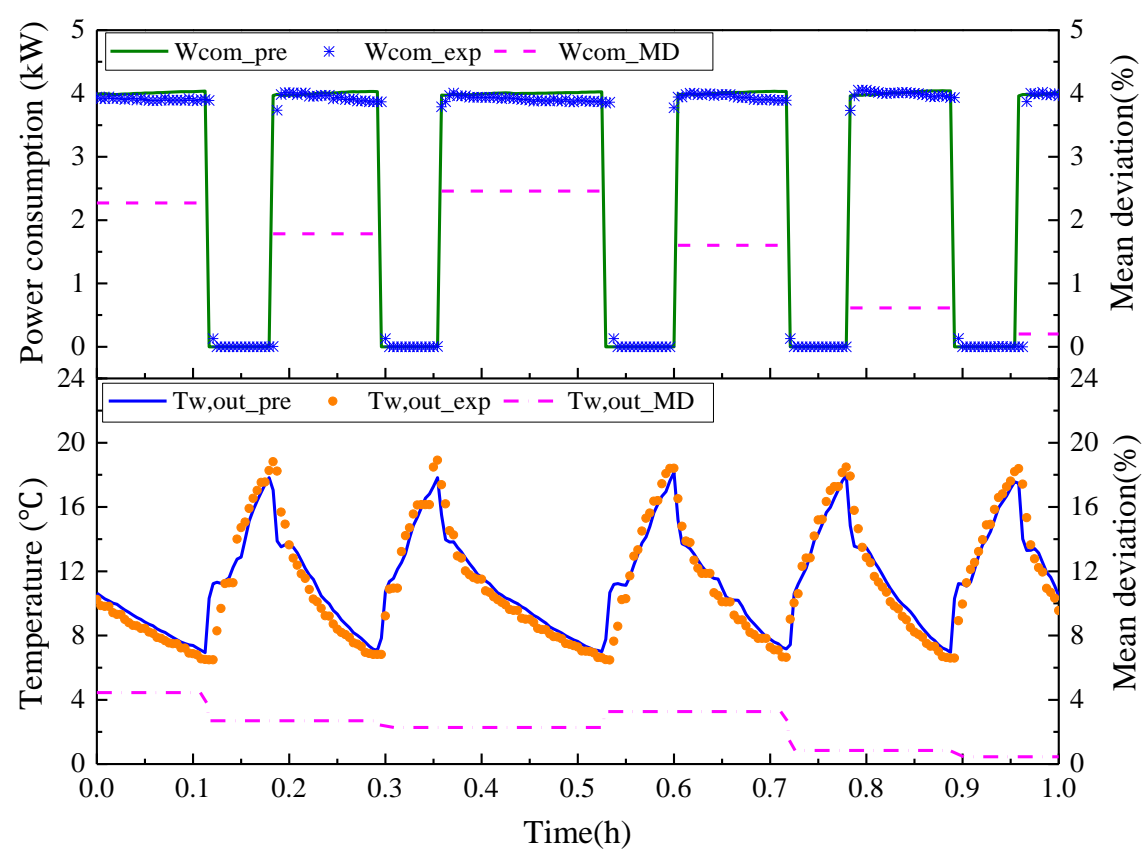

(b) Comparisons of experimental data and model predicted data

Fig. 6 Evaluation of the GSHP model

Note: " $\mathrm{W}_{\text {com" }}$ " indicates the power consumption, and " $\mathrm{T}_{\mathrm{w}, \text { out }}$ " indicates the chilled water temperature at the outlet of the evaporator. "-exp and -pre" indicate the experimental results and predicted results by using the model respectively. "-MD" indicates the mean deviation.

For the GSHE model, $U A_{\mathrm{GS}}$ is the only parameter that needs to be identified. As the annual average temperature of the soil under the ground of about 10 meters maintains in Wuhan is around $18{ }^{\circ} \mathrm{C}$ (Yang et.al 2014), $T_{\text {soil }}$ was set to be $18{ }^{\circ} \mathrm{C}$. Using the operating data of the GSHE in July 7, $U A_{\mathrm{GS}}$ was identified as $U A_{\mathrm{GS}}=2670 \mathrm{~W} / \mathrm{K}$. Once again, the operating data in other summer days were used for validation. An example is shown in Fig 7 where the data were collected in July 9. It can be seen that the predicted water temperature matches well with the measurements. The relative error varied between $-5 \%$ and $5 \%$. It also shows that the GSHE model may predict the outlet cooling water temperature accurately. 


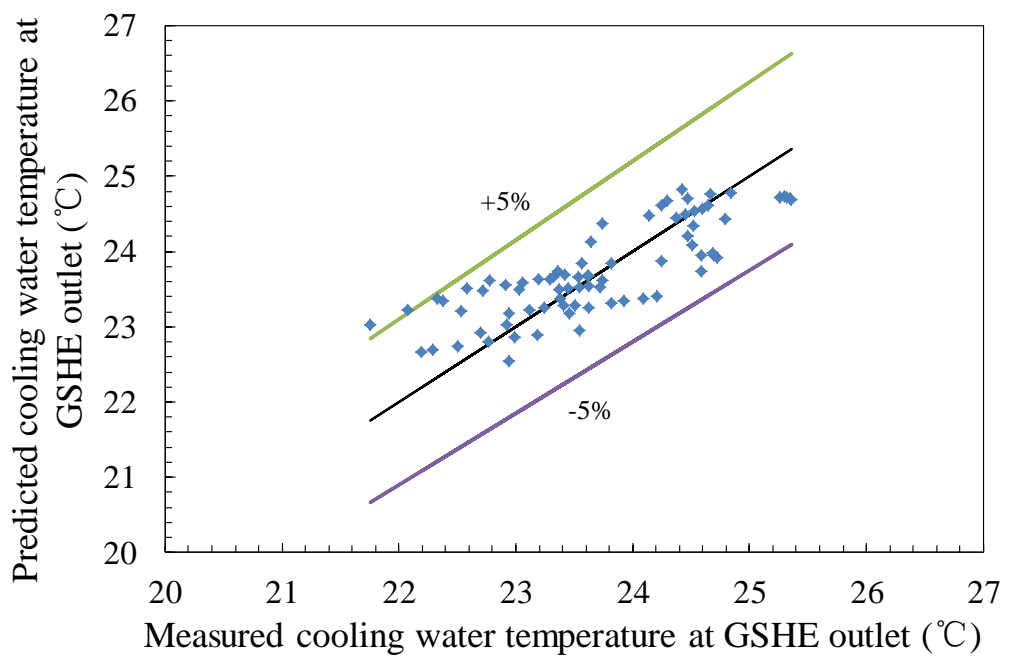

Fig. 7 Evaluation of the GSHE model

\section{Results and Analysis}

After the heat pump model and the GSHE model were validated, the simulation platform was used as an 'actual system' to test the optimization algorithm. The results and analysis were detailed below.

\subsection{Boundary conditions for the results}

In the simulation tests, occupancy, lighting and equipment loads and weather conditions were specified according to the actual operation conditions of the test facility shown in Fig. 4. The profile of total heat gain is shown in Fig. 8, in which from the lunch time was set from 12:00 to 14:00. The outdoor air temperature and humidity in a summer day and a spring day were used and shown in Fig. 9(a) and 9(b) respectively. The occupancy number was set to 20, and the outdoor air flow rate was designed to be $30 \mathrm{~m}^{3} / \mathrm{h}$ for each occupancy according to the ASHRAE standard (ASHRAE 2004). The cooling loads (including total cooling load and sensible heat load) of the summer day and the spring day are given in Fig. 10(a) and 10(b) respectively. The set-point of the indoor air temperature was set $25{ }^{\circ} \mathrm{C}$. The air-conditioning worked from 8:00 am to 20:00 pm, and the sampling interval for the local control algorithms 
was 15 seconds. The boundary conditions for each test were the same.

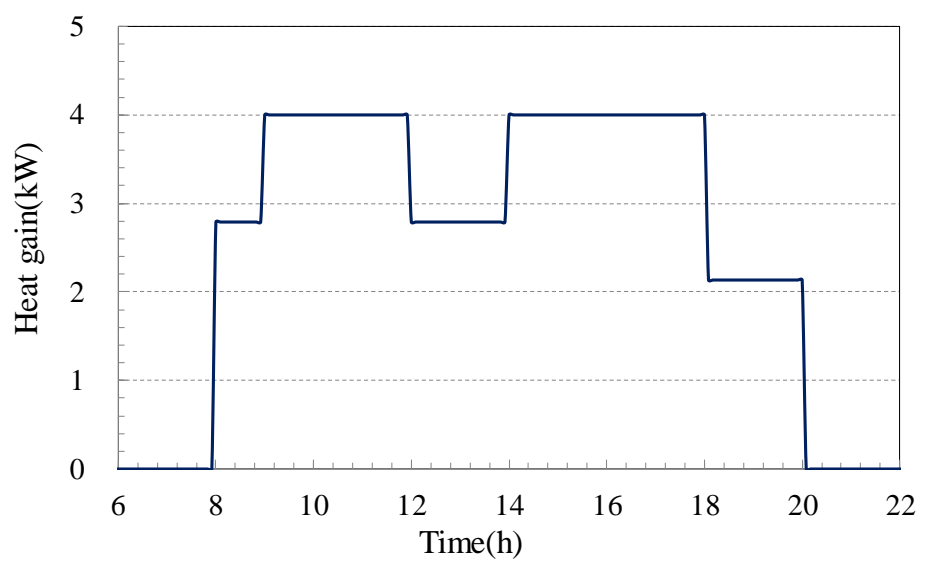

Fig. 8 Profile of the total heat gain of the occupancy, lighting and equipment

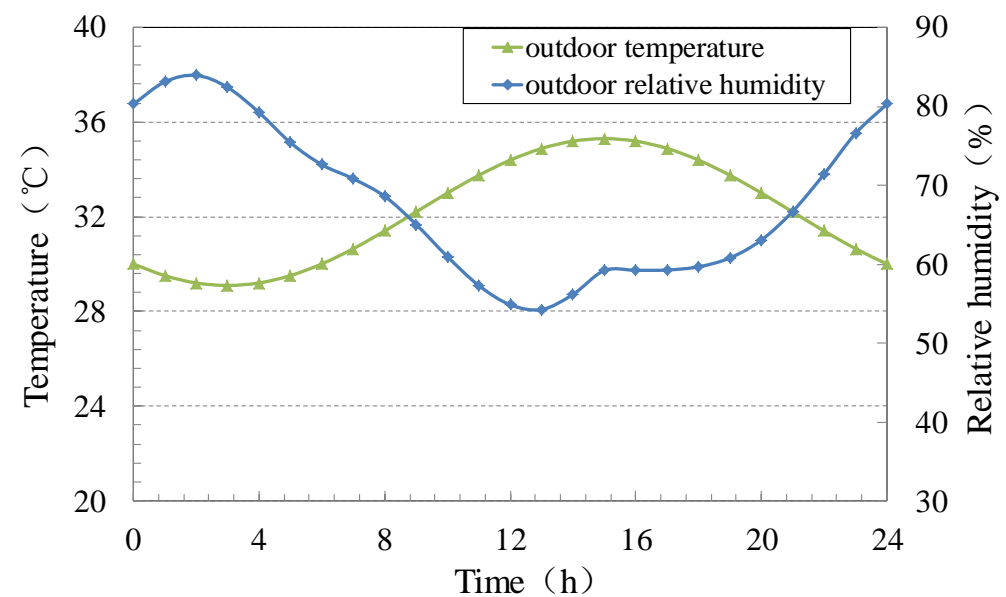

(a) A summer day

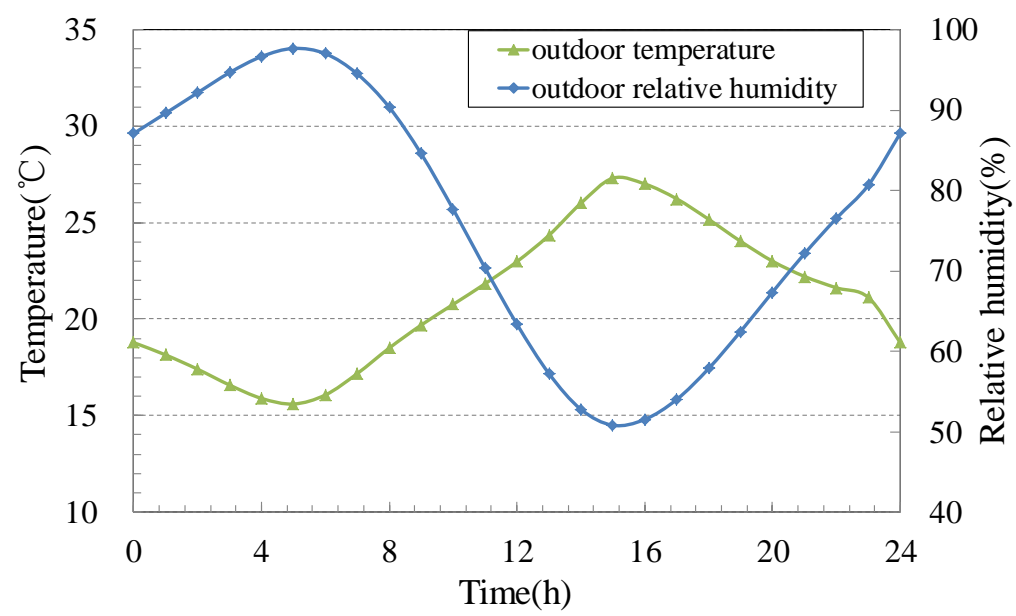

(b) A spring day

Fig. 9 Weather profiles of a summer day and a spring day 


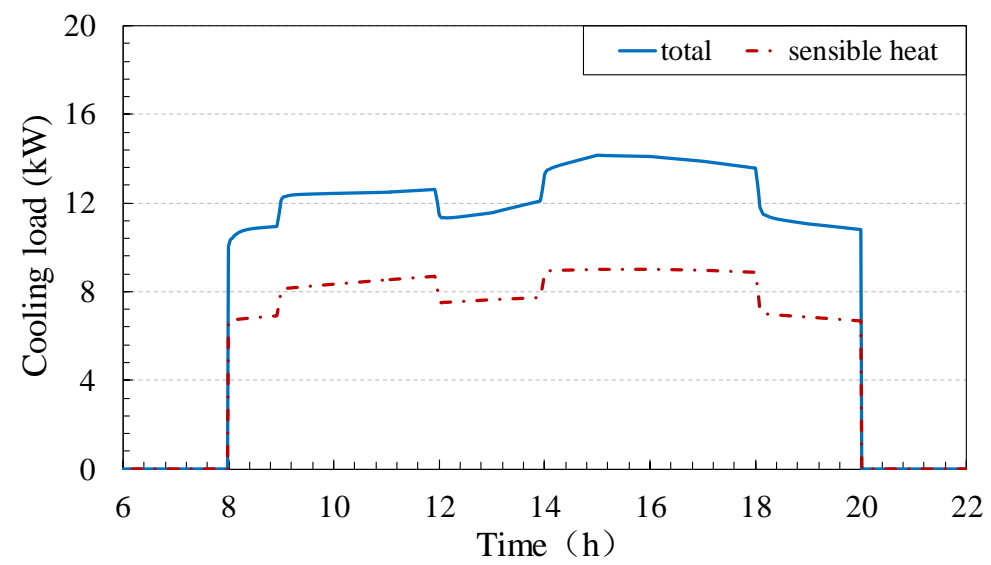

(a) A summer day

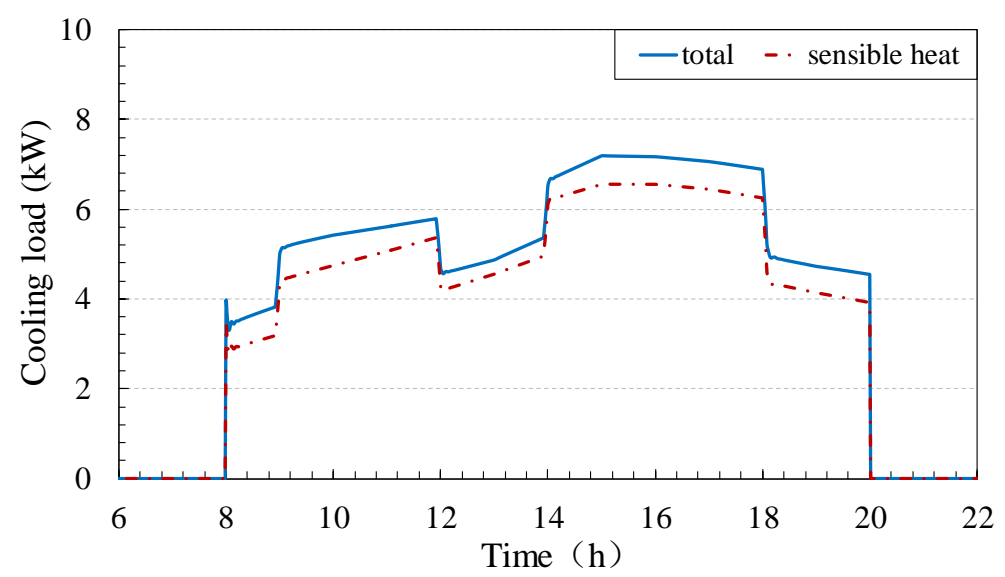

(b) A spring day

Fig. 10 Cooling load profiles of the summer day and the spring day

\subsection{Identification of the models used in the optimization algorithm}

Before validating the models used in the optimization algorithm, the minimal water volume inside the chilled water loop was firstly investigated. As the allowed maximum number of the GSHP start-ups per hour was two times and both the minimum values of $t_{\text {on }}$ and $t_{\text {off }}$ were 180 seconds (given by the manufacture), the minimum size of the water tank for the designed operation condition was $0.250 \mathrm{~m}^{3}$. Therefore, a water tank with the capacity of $0.250 \mathrm{~m}^{3}$ was added to the chilled water flow loop. 
As the optimization algorithm needs a mean power model of GSHP in one on/off cycling period in the form of Eq. (18), an AHU model in the form of Eq. (23) and a mean cooling capacity model of the heat pump over the on-time in one on/off cycle in the form of Eq. (26), they were identified and validated using the data generated from the simulation platform.

To identify the GSHP mean power model (i.e. the coefficients $c_{0}-c_{3}$ ), the training data were generated by the simulation platform (with the configuration specified in Section 4.1) when the room temperature set point $\mathrm{T}_{\mathrm{a} \text {,set }}$ was fixed at $25{ }^{\circ} \mathrm{C}$ and the PLR was varied from $30 \%$ to $100 \%$ (including both summer and spring days). These four coefficients were identified as $c_{0}=-0.0008, c_{1}=0.2372, c_{2}=253.4778, c_{3}=1.2957$. Different data were used for validation and the result is shown in Appendix A.1.

To identify the AHU model in the form of Eq. (23) (i.e. the coefficients $a_{0}-a_{3}$ ), the total cooling load $q_{l}$ was changed from the rated load (full load) to $30 \%$ of the full load (corresponding to the PLR from $100 \%$ to $30 \%$ ). These four coefficients were identified as $a_{0}=1.6538, a_{1}=0.8126, a_{2}=0.0242$ and $a_{3}-0.0608$. Similarly, the validation was done using different data and the result is shown in Appendix A.2.

To identify the mean cooling capacity model of the heat pump over the on-time in one on/off cycle in the form of Eq. (26) (i.e. the coefficients $b_{0}, b_{1}$ ), the CHWR temperature set-point $T_{\mathrm{w}, \text { set }}$ was changed from $12{ }^{\circ} \mathrm{C}$ to $16{ }^{\circ} \mathrm{C}$. These two coefficients $b_{0}$ and $b_{1}$ were identified as $b_{0}=8.7967, b_{1}=0.2541$. Once again, the validation was done using different data and the result is given in Appendix A.3. 


\subsection{Performance evaluation of the optimization}

The optimization algorithm was assessed from the room temperature control performance, GSHP on/off frequency and the total energy consumption. To facilitate the discussion, the proposed optimization strategy was compared with a basic control strategy, in which $T_{\mathrm{w}, \text { set }}$ and $\Delta T_{\mathrm{w}}$ are fixed on their rated values. Note that both strategies were compared when they were applied to the same system.

\section{Space temperature control performance}

In the summer day, the space air temperature was plotted in Fig. 11. Both the optimization strategy and the basic control strategy achieved good control robustness. The average absolute tracking error from 8:00 to $20: 00$ was $0.030{ }^{\circ} \mathrm{C}$, while it was $0.023{ }^{\circ} \mathrm{C}$ when the basic control strategy was used. In the optimization strategy, $T_{\mathrm{w}, \text { set }}$ and $\Delta T_{\mathrm{w}}$ were adjusted according to the cooling load in order to minimize the overall energy consumption, and the variation of $T_{\mathrm{w}, \mathrm{set}}$ and $\Delta T_{\mathrm{w}}$ were shown in Fig. 12(a). Note that when the cooling load increased sharply (which can be seen from Fig. 10(a)) at 9:00 and 14:00, the optimization strategy cannot track the change timely so that the large spikes were observed.

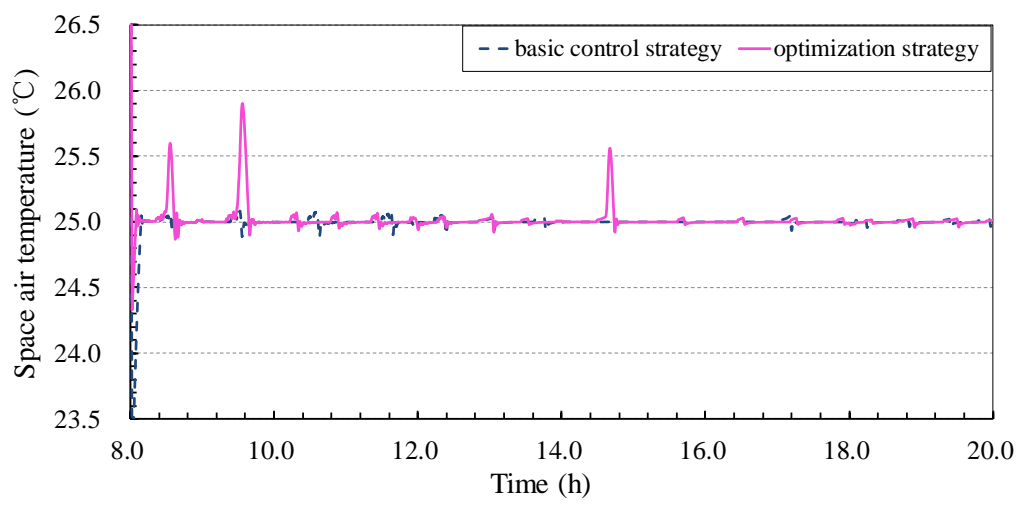

Fig. 11 The space air temperature in a summer day 


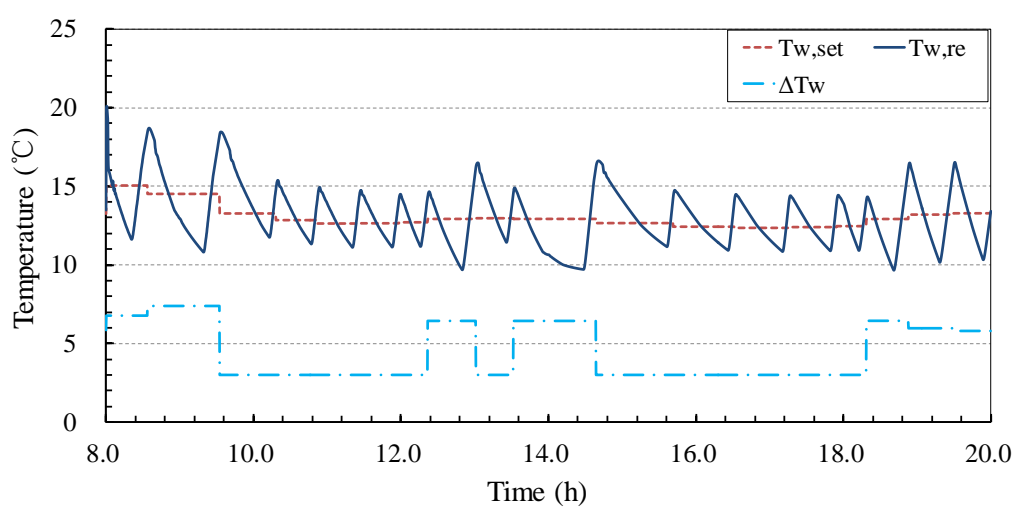

(a) Optimization strategy

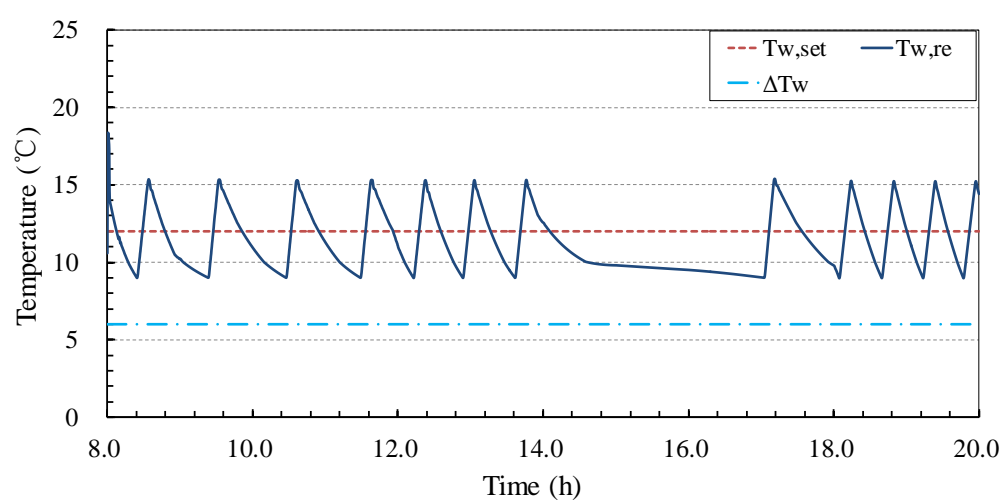

(b) Basic control strategy

Fig. 12 The CHWR temperature profile in a summer day

In the spring day, the thermal response of the space air was more sensitive to the interference of the GSHP on/off. Fig. 13 shows the space air temperature in the spring day. It can be seen that the space air temperature control was more robust when the optimization strategy was used. The average absolute tracking error from 8:00 to 20:00 was $0.059{ }^{\circ} \mathrm{C}$, while it was $0.376{ }^{\circ} \mathrm{C}$ when the basic control strategy was used. The number of the large spikes by using the optimization was much less than that by using the basic control strategy.

Under the light cooling load condition, the cooling amount delivered to the room was larger than the cooling demand. In this case, the basic control strategy cannot adjust the variation 
range of the CHWR temperature (as shown in Fig. 14(b)) to maintain the space air temperature at the set-point well. However, the optimization strategy was able to increase the minimum value of the CHWR temperature to reduce the minimum cooling amount to match the cooling demand as shown in Fig. 14(a). Similarly, when the cooling load decreased sharply as shown Fig. 10(b) at 12:00 and 18:00, the optimization strategy cannot track the change timely, and the large spikes were also observed.

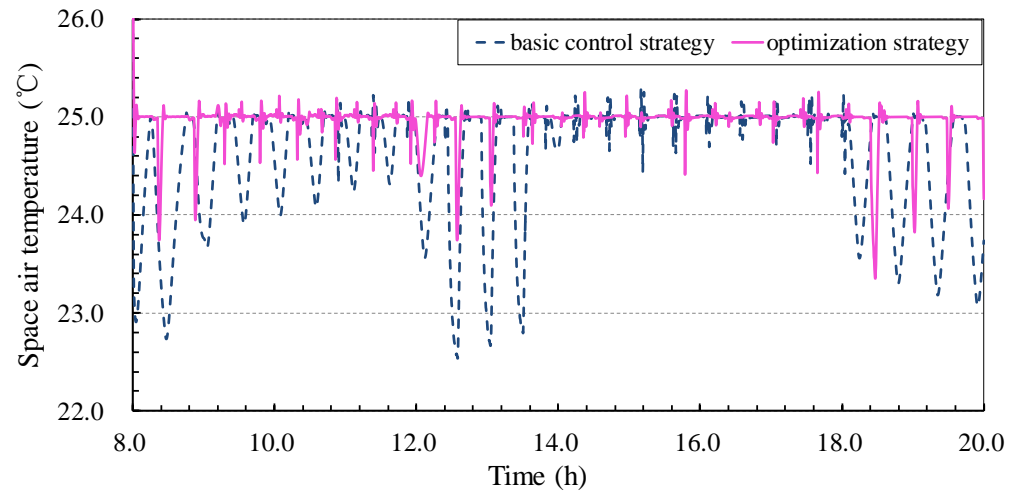

Fig. 13 Control performance of the space air temperature in a spring day

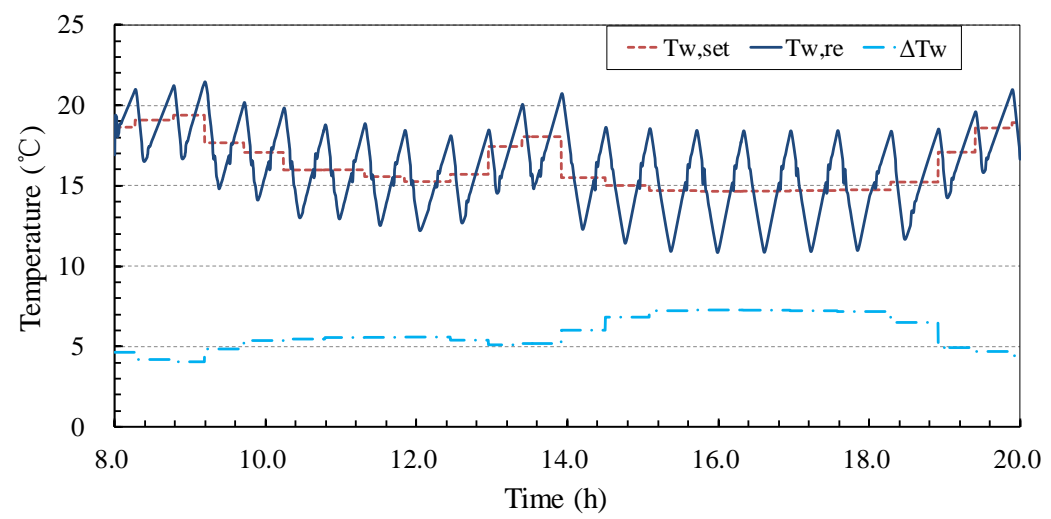

(a) Optimization strategy 


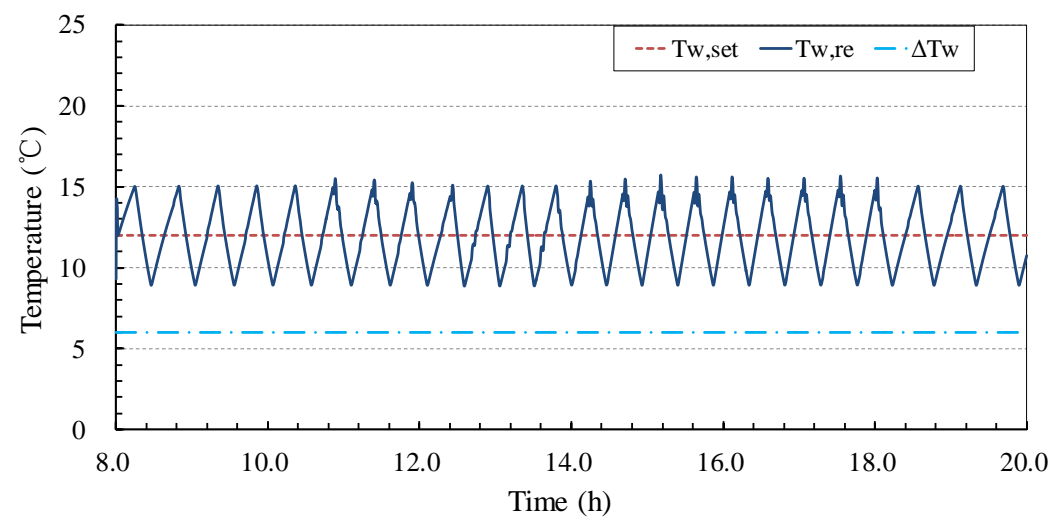

(b) Basic control strategy

Fig. 14 CHWR temperature profile at the light load condition

\section{GSHP start-ups number}

The start-ups number of the GSHP in the summer day and the spring day were listed in Table 5. In both control strategies, the constraint on the GSHP start-ups number was satisfied. In the summer day, as $\Delta T_{\mathrm{w}}$ was reset to a smaller value than the rated value during most of the operation time in the optimization strategy, the start-ups number of the GSHP was larger when compared with the basic control strategy as shown in Fig. 15. In the spring day, $\Delta T_{\mathrm{w}}$ was reset to a larger value than its rated value from 15:00 to 19:00 as shown in Fig. 14, which results in a slightly smaller on/off number when compared with the basic control strategy.

Table 5 Start-ups number in 12 hours

\begin{tabular}{ccc}
\hline Load conditions & Summer day & Spring day \\
\hline Num-bas & 13 & 24 \\
Num-opt & 18 & 22
\end{tabular}

Note: "-bas and -opt" indicate the basic control strategy and the optimization strategy respectively. 


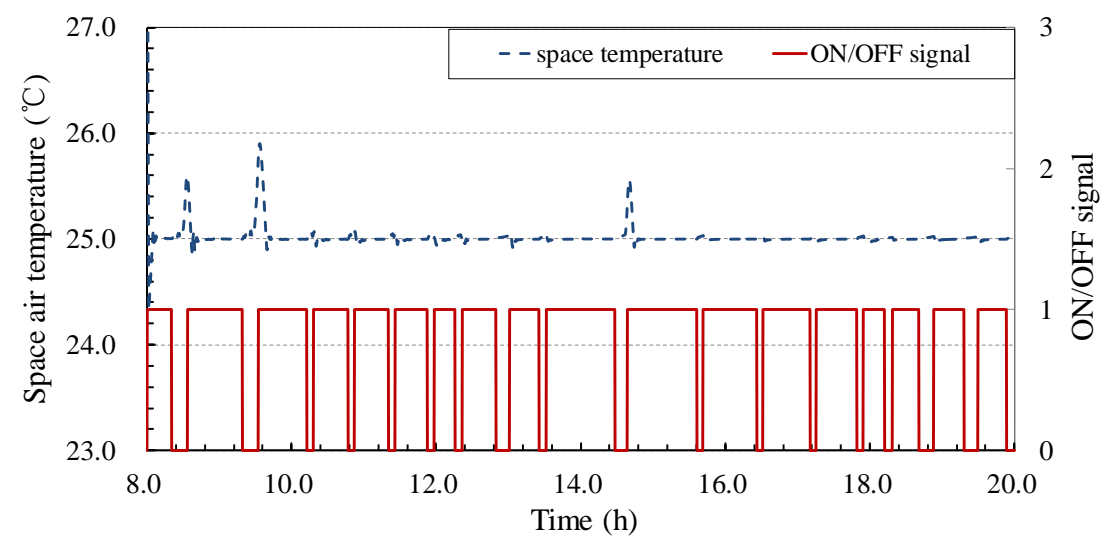

(a) Optimization strategy

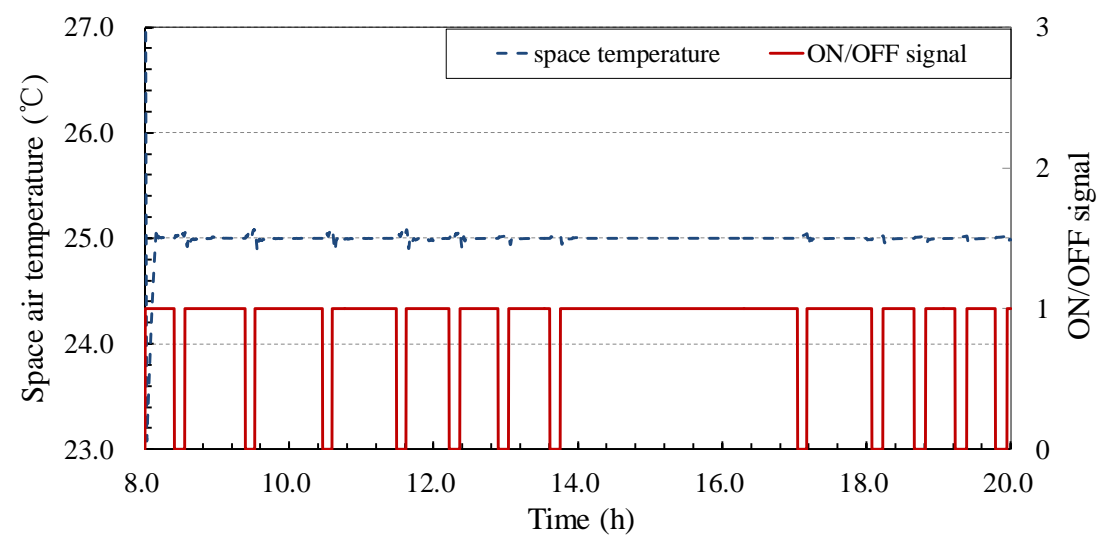

(b) Basic control strategy

Fig. 15 Start-ups number of the GSHP in the summer day

\section{Energy performance}

The energy performance of the optimization strategy was also compared with that of the basic control strategy. A typical spring day and summer day were considered, representing $35 \%$ and $80 \%$ of the full load condition respectively. The daily average energy consumption of the system was listed in Table 6. It can be seen that the optimization strategy achieved a better energy performance both in summer day and in spring day. In the summer day, the energy consumption of the GSHP from 8:00 to 20:00 decreased $2.68 \mathrm{kWh}$ (i.e., $6.34 \%$ ), while that of the fan increased $1.04 \mathrm{kWh}$ (i.e., $27.59 \%$ ). The total energy consumption reduced 1.64 $\mathrm{kWh}$, i.e., $2.97 \%$ of the total energy consumption. In the spring day, the energy consumption of the GSHP from 8:00 to 20:00 decreased $4.31 \mathrm{kWh}$ (i.e., $21.15 \%$ ), while that of the fan 
increased $1.25 \mathrm{kWh}$ (i.e., $53.42 \%$ ). The total energy consumption was reduced $3.06 \mathrm{kWh}$ (i.e., $9.59 \%$ of the total value) when compared with that by using the basic control strategy. The results show that the optimization strategy can efficiently reduce the energy consumption of the overall system, especially under partial load conditions.

Table 6 Energy consumption of 12 hours in the summer day and the spring day

\begin{tabular}{|c|c|c|c|c|}
\hline \multirow{2}{*}{$\begin{array}{c}\text { Load } \\
\text { conditions }\end{array}$} & \multirow[b]{2}{*}{ Equipment } & \multicolumn{2}{|c|}{ Energy consumption (kWh) } & \multirow{2}{*}{$\begin{array}{c}\text { Energy saving } \\
(\%)\end{array}$} \\
\hline & & $\begin{array}{c}\text { Basic control } \\
\text { strategy }\end{array}$ & $\begin{array}{c}\text { Optimization } \\
\text { strategy }\end{array}$ & \\
\hline \multirow{4}{*}{ Summer day } & Heat pump & 42.25 & 39.57 & 6.34 \\
\hline & Fan & 3.77 & 4.81 & -27.59 \\
\hline & Pumps & 9.2 & 9.2 & - \\
\hline & Overall system & 55.22 & 53.58 & 2.97 \\
\hline \multirow{4}{*}{ Spring day } & Heat pump & 20.38 & 16.07 & 21.15 \\
\hline & Fan & 2.34 & 3.59 & -53.42 \\
\hline & Pumps & 9.2 & 9.2 & - \\
\hline & Overall system & 31.92 & 28.86 & 9.59 \\
\hline
\end{tabular}

Note: “+” indicates energy saving, and "-" indicates energy increasing.

\section{Application issues}

The proposed strategy is not difficult to use. For an existing GSHP integrated A/C system, the water volume in the chilled water loop can be easily calculated. When the allowed GSHP maximum start-ups number is specified, the required volume is calculated by Eq. (2), which should be compared with the current water volume to decide whether a water tank is needed. The real-time optimization of $T_{\mathrm{w}, \mathrm{set}}$ and $\Delta T_{\mathrm{w}}$ needs a mean power model of GSHP in one on/off cycling period (Eq. (18)), an AHU model (Eq. (23)) and a mean cooling capacity 
model of the heat pump over the on-time in one on/off cycle (Eq. (26)). Those models should be identified using the data collected from commissioning. As the system is in a small-scale, data generation will not be difficult. Another application issue is the online load estimation, which can be done using energy meters based on the calculation shown in Eqs. (28)-(29). Nowadays building automation system (BAS) is widely used to monitor and control A/C systems. A feasible way to implement the proposed strategy is to integrate it into a BAS system.

\section{Conclusion}

This paper presents an optimization strategy for a GSHP-integrated A/C system in order to optimize the overall system energy consumption without violating the allowed GSHP maximum start-ups number and degrading the space air temperature control performance. This optimization strategy is schemed with two steps. Firstly, the water volume inside the chilled water loop is checked whether it is enough to satisfy the allowed GSHP maximum start-ups number per hour at the design condition. Secondly, an optimization algorithm is developed to optimize the system settings $\left(\Delta T_{\mathrm{w}}\right.$ and $\left.T_{\mathrm{w}, \mathrm{set}}\right)$ by minimizing the total power of the system. The performance of the optimization strategy is compared with the basic control strategy (i.e., the system operates at the predefined rule). The results show that the optimization strategy can improve the robustness of the space air temperature control significantly and reduce the system energy consumption obviously in spring days, i.e. under light load conditions. The energy consumption of the GSHP was reduced by $21.15 \%$ and the overall system was reduced by $9.59 \%$. In the summer day, both the optimization strategy and the base control strategy can achieve a robust control of the space air temperature, while the energy consumption of the overall system is slightly smaller (reduced by $2.97 \%$ ) when the optimization strategy is used. The results also show that when the water volume in the chilled 
water loop is sufficient, both strategies can guarantee the GSHP start-ups number specified by customers being satisfied.

\section{Acknowledgements}

This work presented in this paper is financially supported by a grant (No. 51178201) of National Science Foundation of China and supported by the research fund of "Program for New Century Excellent Talents in University" (No. 2011CDB292) as well as a grant (No. 2015QN116).

\section{Appendix A}

\section{A.1 Validation of the mean power consumption model of the overall system}

Figure A.1 presented the validation of the mean power consumption model of Eq. (18) by using the 'operation data' collected from a simulation platform as shown in Fig. 5, which was constructed based on an actual test facility as shown in Fig. 4. The 'measurement data' are the power consumptions of the heat pump, pumps and fan. These data were collected in widely varying conditions, which covered the possible operation conditions of the actual system. It can be seen that the model may predict the overall energy consumption of the GSHP system well. The largest absolute prediction error is $2.63 \%$, and the average absolute error is $0.67 \%$.

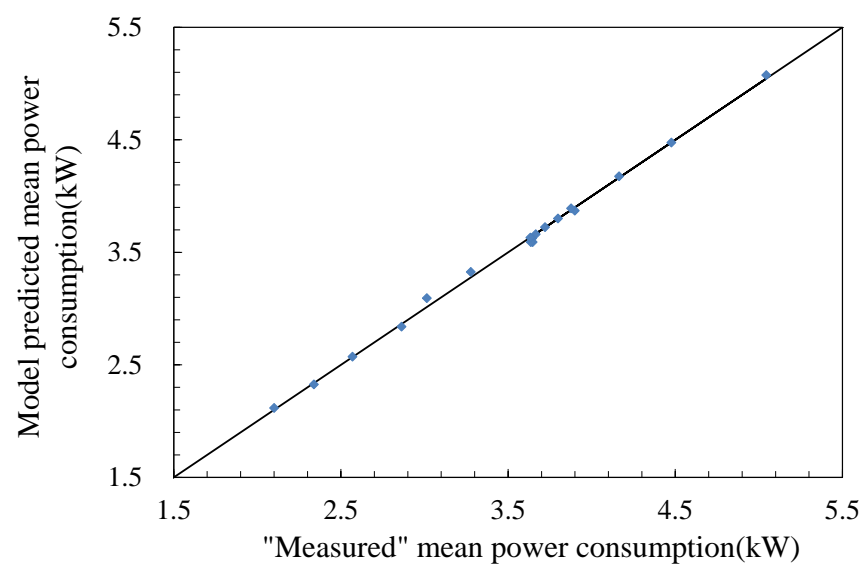

Fig. A.1 Validation of the mean power consumption model of the overall system in one GSHP 
on/off cycling period

\section{A.2 Validation of the simplified AHU model}

The simplified AHU model, described by Eq. (23), was validated by using the 'operation data' collected from the simulation platform. The 'measurement data' include CHWR temperature, water temperature at the inlet of the AHU, supply air temperature and supply air flow rate. The validation results were given by Fig. A.2. It can be seen that the model may predict the CHWR temperature accurately in a large variation range. The largest absolute prediction error is $1.01 \%$, and the average absolute error is $0.42 \%$.

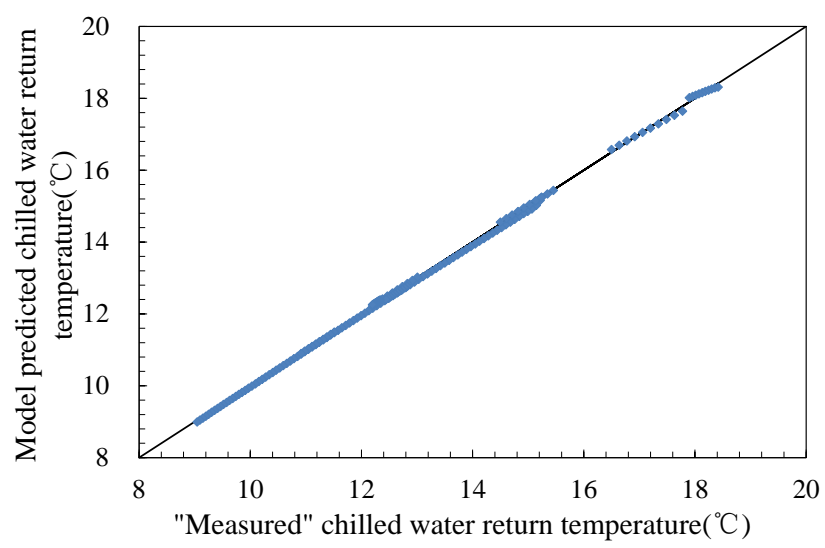

Fig. A.2 Validation of the simplified AHU model

A.3 Validation the mean cooling capacity model over the on time during on/off cycling period The mean cooling capacity model of Eq. (26) was validated by using the 'operation data' collected from the simulation platform as shown in Fig. A.3. When the CHWR temperature set-point changes from $10{ }^{\circ} \mathrm{C}$ to $17{ }^{\circ} \mathrm{C}$, the largest absolute prediction error is $0.18 \%$, and the average absolute error is $0.1 \%$. The reliability and accuracy of the model is acceptable in this study. 


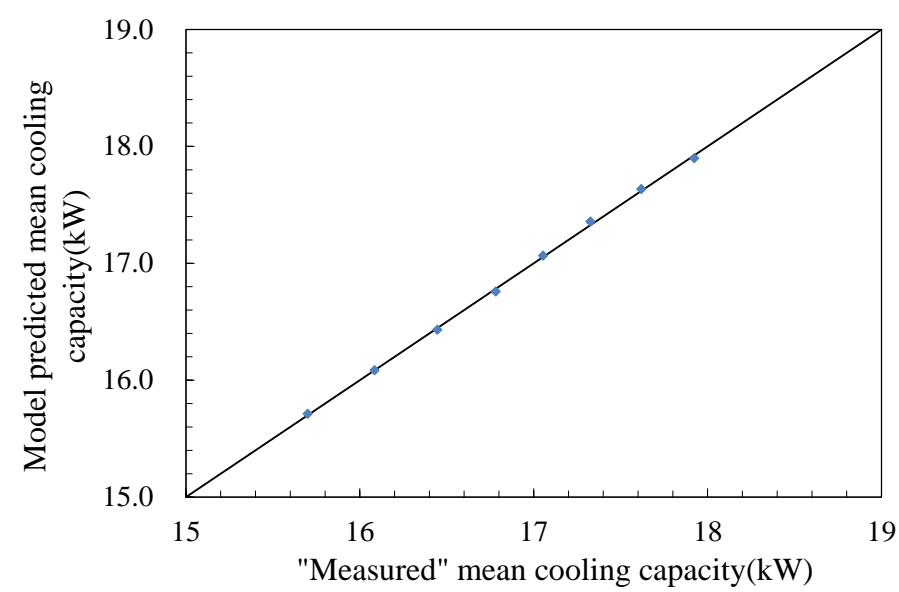

Fig. A.3 Validation of the mean cooling capacity model

\section{References}

[1] ASHRAE. ASHRAE Handbook-Fundamentals. Atlanta: American Society of Heating, Refrigerating and Air-Conditioning Engineers, Inc., USA; 2009.

[2] Shen P, Lukes JR. Impact of global warming on performance of ground source heat pumps in US climate zones. Energy Conversion and Management 2015; 101:632-43.

[3] ASHRAE. ASHRAE Handbook-HVAC applications. SI ed. Atlanta, USA: ASHRAE Inc.; 2011.

[4] Afram A, Janabi-Sharifi F. Theory and applications of HVAC control systems-A review of model predictive control (MPC). Building and Environment 2014; 72:343-355.

[5] Huang GS, Wang SW, and Xu XH. A robust model predictive control strategy for improving the control performance of air conditioning systems. Energy Conversion and Management 2009; 50(10):2650-8.

[6] Sun YJ, Huang GS, Li ZW, Wang SW. Multiplexed optimization for complex air conditioning systems. Building and Environment 2013; 65:99-108.

[7] Sayyaadi H, Amlashi EH, Amidpour M. Multi-objective optimization of a vertical ground source heat pump using evolutionary algorithm. Energy Conversion and Management 2009; 50(8): 2035-46. 
[8] Kusiak A, Tang F, Xu G. Multi-objective optimization of HVAC system with an evolutionary computation algorithm. Energy 2011; 36(5):2440-9.

[9] Chang YC, Lin FA, Lin CH. Optimal chiller sequencing by branch and bound method for saving energy. Energy Conversion and Management 2005; 46:2158-72.

[10] Ferreira PM, Ruano AE, Silva S, Conceicao EZE. Neural networks based predictive control for thermal comfort and energy savings in public buildings. Energy and Buildings 2012; 55:238-51.

[11] Chang YC, Chen WH, Lee CY, Huang CN. Simulated annealing based optimal chiller loading for saving energy. Energy Conversion and Management 2006; 47:2044-58.

[12] Spindler HC, Norford LK. Naturally ventilated and mixed-mode buildings-part II: optimal control. Building and Environment 2009; 44:750-61.

[13] Ling KV, Maciejowski J, Richards A, Wu BF. Multiplexed model predictive control. Automatica 2012; 48: 396-401.

[14] Sarabia D, Capraro F, Larsen LFS, Prada CD. Hybrid Control of a Supermarket Refrigeration System, in: Proc. American Control Conference, New York, USA, 2007; pp:4178-85.

[15] Arteconi A, Brandoni C, Rossi G, Polonara F. Experimental evaluation and dynamic simulation of a ground coupled heat pump for a commercial building. International Journal of Energy Research 2013; 37(15):1971-80.

[16] Schibuola L, Tambani C, Zarrella A, Scarpa M. Ground source heat pump performance in case of high humidity soil and yearly balanced heat transfer. Energy Conversion and Management 2013; 76:956-70.

[17] Corberan JM, Finn DP, Montagud CM, Murphy FT, Edwards KC. A quasi-steady state mathematical model of an integrated ground source heat pump for building space control. Energy and Buildings 2011; 43:82-92. 
[18] Montagud C, Corberan JM, Montero A. In situ optimization methodology for the water circulation pumps frequency of ground source heat pump systems. Energy and buildings $2014 ; 68: 42-53$.

[19] Karlsson F, Fahlen P. Capacity-controlled ground source heat pumps in hydronic heating systems. International Journal of Refrigeration 2007; 30:221-9.

[20] Madani H, Claesson J, Lundqvist P. Capacity control in ground source heat pump systems part II: Comparative analysis between on/off controlled and variable capacity systems. International Journal of Refrigeration 2011; 34:1934-42.

[21] Zhao L, Zhao LL, Zhang Q, Ding GL. Theoretical and basic experimental analysis on load adjustment of geothermal heat pump systems. Energy Conversion and Management $2003 ; 44: 1-9$.

[22] Beghi A, Cecchinato L. Modelling and adaptive control of small capacity chillers for HVAC applications. Applied Thermal Engineering 2011; 31:1125-34.

[23] Gao JJ, Huang GS, Xu XH. Space temperature control of a GSHP-integrated air-conditioning system. Energy and Buildings 2015; 108:127-36.

[24] Madani H, Claesson J, Lundqvist P. A descriptive and comparative analysis of three common control techniques for an on/off controlled Ground Source Heat Pump (GSHP) system. Energy and Buildings 2013; 65:1-9.

[25] Cervera-Vázquez J, Montagud C, Corberán J M. In situ optimization methodology for ground source heat pump systems: Upgrade to ensure user comfort. Energy and Buildings 2015; 109:195-208.

[26] Huang GS. Model predictive control of VAV zone thermal systems concerning bi-linearity and gain nonlinearity. Control Engineering Practice 2011; 19:700-10.

[27] Huang GS and Filip J. Model-based robust temperature control for VAV air-conditioning system. HVAC\&R Research 2012; 18(3):432-45. 
[28] Dawson Co. Hydronic News of Southern California and Hawaii. Volume 3, Issue 4, May 2007.

[29] Ma ZJ, Wang SW. An optimal control strategy for complex building central chilled water systems for practical and real-time applications. Building and Environment 2009; 44(6):1188-98.

[30] TRNSYS. A transient simulation program: documentation. University of Wisconsin, USA, Solar Energy Laboratory, Version 16; 2004.

[31] Bourdhouxhe JP, Grodent M and Lebrun J. HVAC-TOOLKIT: A toolkit for primary HVAC system energy calculation. ASHRAE, 1999.

[32] Wang S, Wang J, Burnett J. Mechanistic model of centrifugal chillers for HVAC system dynamics simulation, Building Services Engineering Research \& Technology 2000; 21(2):73-83.

[33] Yang J, Xu L, Hu P, Zhu N, Chen X. Study on intermittent operation strategies of a hybrid ground-source heat pump system with double-cooling towers for hotel buildings. Energy and Buildings 2014; 76:506-12.

[34] Wang SW, Dynamic simulation of building VAV air-conditioning system and evaluation of EMCS on-line control strategies. Building and Environment 1999; 34(6):681-705.

[35] Xu XH, Wang SW, Shi WZ. A robust sequencing control strategy for air-handling units. Building Services Engineering Research \& Technology 2004; 25(2):141-58.

[36] Haves P, Dexter AL. Simulation of local loop controls: Proceedings of Building, IBPSA. Vancouver; 1989.

[37] ASHRAE. ASHRAE Standard 62.1-2004. Ventilation for Acceptable Indoor Quality, Atlanta; 2004. 